\title{
Sexuality and the city: The geography of LGBT political participation in the United States
}

\author{
Jack Thompson ${ }^{*} \quad$ Stuart J. Turnbull-Dugarte ${ }^{\dagger}$ \\ July 15, 2021
}

\begin{abstract}
The literature on LGBT participation is growing, but there is still little empirical analysis on the importance of urbanicity in shaping Queer activism. In this paper, we address this critical gap by examining how patterns of participation among LGBT Americans vary by geographic context. Using data from the 2020 Cooperative Election Study (CES) to explore how patterns of LGBT participation differ across the urbanrural interface, we find that individuals identifying as LGBT living in urban areas exhibit higher rates of participation than those living in rural areas, and that these results hold across multiple urban-rural classification schemes. Estimating a multilevel model that leverages local-level data on the density of the LGBT population, we also provide strong empirical validation of the theoretical effects of intragroup contact and mobilization on LGBT participation in large metro areas. When we limit our sample to respondents living in the 55 largest metro areas in the US but vary the metro-level percentage of LGBT individuals, we find that LGBT individuals living in metro areas with a higher percentage of LGBT individuals exhibit higher rates of participation relative to metro areas with a lower percentage of LGBT individuals. The results indicate that urban contexts foster Queer participation by engendering intragroup contact and mobilization among LGBT populations.
\end{abstract}

Keywords: intragroup contact, LGBT, mobilisation, political participation, urban, rural

${ }^{*}$ Nottingham Trent University. Email: n0429992@ntu.ac.uk

${ }^{+}$University of Southampton 


\section{Introduction}

A number of works examine the antecedents of robust political participation among different social strata in democratic polities. In recent decades, scholars have built on these works by examining how sexual and gender identity shape political participation (Bowers \& Whitley 2018, Perez 2014, Swank 2019, Turnbull-Dugarte \& Townsley 2020). Being active in the political process - whether it be via institutionalized forms such as voting in elections, or via non-institutionalized forms such as signing a petition - is particularly important for individuals with LGBT identities, since robust participation functions as means of maximizing inclusiveness, and aids the contribution of policy output from elected officials to further utility-maximizing group welfare (Turnbull-Dugarte \& Townsley 2020).

The literature on LGBT participation is growing, but there is still little empirical analysis into the importance of urbanicity in shaping Queer activism. This omission is somewhat surprising; Going back to the work of Castells (1983), there has been a longstanding recognition that urban residence is highly conducive to political participation. Increased city size was previously thought to impede participation as individuals may feel as though their influence is significantly diminished in larger areas (Dahl 1967). However, contemporary evidence suggests that population concentration facilitates the creation of dense social networks that engender rather than impede participation in large urban areas. As individuals in close physical proximity come into contact, they are likely to share concerns on common problems, and organize for civic action (Tavares \& Carr 2016), leading to the emergence of a "critical mass" (Tarrow 2011). Proximity also enhances the opportunities for group mobilization. For instance, political associations are more successful in captivating the interest of new members because geographic propinquity allows significant savings in communication and information dissemination (Foos et al.2021). There are reasons to expect that this model is especially important for understanding Queer participation, since $88.3 \%$ percent of the LGBT Americans live in an urban 
area (Badgett et al. 2019) and recent work draws an empirical link between the clustering of LBT activism within urban centres with the advancement of LGBT rights reforms (Ayoub et al. 2021). Given these theoretical relationships, we therefore provide the first in-depth empirical analysis of how urbanicity shapes LGBT political participation.

Empirically, we examine the geography of LGBT ${ }^{1}$ political participation in the United States using data from the 2020 Cooperative Election Study (CES). In further support of a sexuality/gender identity "gap" in participation (Hertzog 1996, Turnbull-Dugarte \& Townsley|2020, Page 2018, Sherrill \& Flores 2014), we first find that, on average, individuals with LGBT identities are more likely than cisgender/straight individuals to participate in a variety of political activities. The participation-inducing association between LGBT group identity is robust across intersectional analyses based on both gender and race. Exploring patterns of LGBT participation across the urban-rural interface, we next find that LGBT identifying individuals living in urban areas exhibit higher rates of participation than those living in rural areas. Furthermore, we find that these results hold across multiple urban-rural classification schemes (Nemerever \& Rogers 2021), thus lending empirical weight to contemporary accounts of the importance of urbanicity in engendering political participation.

Finally, we provide some empirical validation of the theoretical effects of intragroup contact and mobilization on LGBT participation in large metro areas by ways of a multilevel model. Specifically, when we limit our sample to respondents living in the 55 largest metro areas in the US but leverage the variation in the metro-level percentage of LGBT individuals, we find that LGBT individuals living in metro areas with a greater percentage of LGBT individuals exhibit significantly higher rates of participation relative to metro areas with a lower percentage of LGBT individuals. These findings engage directly with

\footnotetext{
${ }^{1}$ When referring to the wider community, scholars have often used the LGBTQI+ or LGBTQIA+ acronym to include individuals who are queer, intersex, asexual, or anyone else with a non-heteronormative sexual/non-cis gender identity. In the dataset we analyze, however, we are only able to identify respondents who are lesbian, gay, bisexual, or trans. Therefore, we use the acronym LGBT for clarity throughout the paper.
} 
the evidence regarding the role of social interactions (Huckfeldt et al.|1993, Putnam|1966), particularly in spatially localised settings (Enos 2017), as the driving force behind political distinctiveness among certain social strata.

\section{Understanding LGBT Political Participation}

While the antecedents of political participation are well mapped within the extant scholarship (Smets \& van ham 2013), the role of LGBT identity in engendering greater participation has traditionally been overlooked. Recently, however, a burgeoning literature is starting to emerge that remedies these deficiencies (Edelman 1993, Hertzog 1996. Lewis, Rogers \& Sherrill 2011, Schaffner \& Senic 2006). One the one hand, the pathway to participation among LGBT individuals has been theorised to reflect the utilitarian decision-making calculus that underpins rational choice theory, which assumes that utility-maximizing voters will cast their ballot for candidates that they perceive will increase their personal welfare (Downs 1957, Olson 1965). In the case of LGBT individuals, whose rights - particularly in the US - have been salient election issues (Campbell \& Monson 2008) and have also been the focus of concrete ballot measures (Abrajano 2010. Klarman 2014), are incentivised to participation in the political process as if "their rights depended on it" (Turnbull-Dugarte \& Townsley 2020). This model ought to be especially relevant for individuals with LGBT identities, since the potential benefits for marginalized groups are often larger than those for nonmarginalized groups.

Indeed, the incentivizing role of group self-interest is strongest when policies proposed by competing candidates are understood to have a significant impact on the everyday life of voter and the group (Lipset 1983). In the particular case of individuals with LGBT identities, this might include changes in the legality of same-sex sexual activity, the recognition of same-sex relationships, and protections from sexual or gender identitybased discrimination in employment. In this respect, we would thus expect individuals 
with LGBT identities to be active in democratic processes in order to protect themselves from potential discrimination from nonmarginalized groups (i.e. the tyranny of the [heteronormatove] majority), pursue reforms to existing anti-LGBT policies, support policies that advance their own economic and social welfare, and protest against their current legal and social position.

On the other hand, psychological models also influence the path to LGBT political participation. For instance, LGBT individuals may participate in the political process in a form of retributory backlash against their lived experience as a marginalised and discriminated minority (Page 2018), because they are angry, anxious, or enthusiastic (Valentino et al. 2011), or because they are motivated to stand up for a cause that they believe in (Klandermans 2002).

While many advances have been made in the equal treatment of the US' LGBT population in recent years - most notably, the decriminalization of same-sex relations in 2003, the provision of same sex marriage in 2015, and the protection of employees from genderidentity based discrimination in 2020 - much discrimination nonetheless persists. ${ }^{2}$ Crucially, this discriminatory treatment can mobilize individuals with LGBT identities to take political action (Page 2018). In this way, experiencing social or institutional ostracisation alongside a desire to expand group welfare may also drive marginalized groups to become politically active by necessity. Similar group-based retributory or defensive activation mechanisms have also been theorised to explain under what conditions individuals marginalised by race are also prone to become politically engaged (Pantojo et al.2001).

Given observable efforts to mobilize individuals with LGBT identities to become politically active in order to advance their welfare and legal rights, and the notable efforts of elites to court the votes of LGBT individuals 3 there is a clear basis to expect LGBT indi-

\footnotetext{
${ }^{2}$ These efforts have also given rise to a conservative backlash (Klarman|2014), and has also engendered heightened political participation among the opponents of LGBT rights (Ayoub \& Page 2020)

${ }^{3}$ Given the aforenoted links between LGBT identity and electoral support for the Democratic Party, it is not surprising to find that Democratic elites are more likely to talk about the LGBTQI+ community in humanizing frames than Republican elites, who, by contrast, tend to use oppositional frames when discussing the LGBT community (Coe et al.2017)
} 
viduals to be more politically engaged and active in the electoral and nonelectoral democratic processes. Indeed, much literature finds that LGBT individuals have an equal, if not greater propensity, than cisgender straight individuals to participate in the political process (Egan, Edelman \& Sherrill 2009, Swank \& Fahs 2013, Turnbull-Dugarte \& Townsley 2020, Perez 2014) 4

Notwithstanding, LGBT individuals face a number of barriers to participation, including discrimination. While discrimination experiences may engender greater oppositional consciousness, thus motivating individuals with LGBT identities to act (Page 2018), it is important to note that states may stymie opportunities which, in turn, limit LGBT participation. For instance, voter ID laws may discriminate against trans individuals because obtaining proper identification that matches their gender identity can be challenging, thus depressing voter registration. Consistent with this observation, Bowers \& Whitley (2018) find that trans individuals who do not have access to gender appropriate ID have a lower propensity to register to vote, and that these effects are intensified in states with registration and voter ID laws.

\section{Queer Activisms Beyond the Urban Periphery}

Though much work notes an important relationship between LGBT identity and political participation, discussions on the role of urbanicity in fostering greater participation among LGBT identifying individual are largely absent within the political science scholarship. Castells (1983) highlights the longstanding recognition that urban residence is highly conducive to political participation and there is also reason to expect that the effects of urban residence on participation are especially salient for individuals with LGBT identities. Indeed, $88.3 \%$ percent of the LGBT population live in an urban area (Badgett

\begin{tabular}{|l|}
\hline \hline${ }^{4}$ In addition to these works, studies also observe noteworthy differences in specific types of participa- \\
tion among LGBT and cisgender straight individuals, with the former exhibiting higher rates of protest \\
\hline participation than the latter (Swank $2019 \mid$ Swank \& Fahs 2019$)$. \\
\hline
\end{tabular}


et al.2019). Even though an overwhelming percentage of the LGBT population lives in an urban area, much work on Queer activism focuses on just a handful of cities with populations greater than one million (Stone 2018). Meanwhile, while the role of smaller cities, suburban areas, and exurban areas in engendering greater participation are ignored altogether. In this section, we therefore explore patterns of Queer activism by type of place to better understand whether large cities are indeed the locales most conducive to LGBT political participation.

\subsection{Large Cities and Queer Activism}

Large cities have long been the principal focus of enquiry in studies of Queer political behavior (Bailey 1999). The postwar transformation of America's large cities facilitated the expansion of LGBT social life. LGBT identity was not an enduring identity but, rather, one that emerged as a consequence of urbanization, which facilitated new forms of social organization into bars, clubs and organizations, and political groups (Rupp \& Taylor 2015). As LGBT individuals move from exurban areas to large urban centers (Annes \& Redlin 2012, Weston 1995), they find themselves better positioned to accumulate power resources, whether it be via better educational or occupational opportunities. The various political, social, and economic incentives from urban living then provide greater opportunities for individuals with LGBT identities to develop visible Queer institutions, including political organizations (Haeberle 1996, Ayoub et al. 2021). The close physical proximity $5^{5}$ of large numbers of individuals with LGBT identities leads to the formation of a "critical mass" (Tarrow 2011), engendering greater communication, ideological development, group identity, collective action as well as group visibility to the heterosexual

\footnotetext{
${ }^{5}$ One could argue that the emergence of online social networking sites and apps such as Grindr mean that physical proximity is no longer so important for fostering communication between LGBT individuals (Becker \& Copeland 2016, Renninger 2018). Nevertheless, it is important to note that individual use of these apps is still conditioned by geographic context. For instance, Grindr users are able to select a preference on the app saying they are interested in networking socially with fellow users. However, when one searches for fellow app users, individuals are sorted by geographic proximity from the users own device, thus lowering the chances of communicating with LGBT individuals who are the most geographically distant.
} 
and cisgender outgroup. For these reasons, individuals with LGBT identities living in large cities are better poised to challenge anti-LGBT discrimination - in part because they have the advantage of being spatially clustered within urban centres that are often home to political seats of power (Anthony 2014) - and are also able to move into more fluid competitive relations with cisgender straight individuals.

It is not the case, however, that all cities are central to the scholarly focus of LGBT activisms. The so-called four "great cities" - namely, Chicago, Los Angeles, New York City, and San Francisco - get a disproportionate amount of attention from social scientists studying LGBT behaviors and attitudes..$^{6}$ A primary emphasis on these locations is problematic, since cities such as Austin, Denver, Orlando, Portland, and Seattle, all have a larger percentage of LGBT-identifying individuals than "great" cities such as New York City (Conron et al. 2020), and yet are rarely mentioned in the academic scholarship. Furthermore, studies of Queer activisms primarily focus on small sections of these four "big cities," with an emphasis on the importance of gay enclaves, gay villages, and "gayborhoods" (Orne 2017).7 These spaces are important loci for community building among LGBT individuals and serve as vehicles for building political constituencies (Ghaziani 2015). 8

${ }^{6}$ Stone (2018) notes that 62 percent of social science studies into LGBT life are primarily conducted in either one or a combination of these locales.

${ }^{7}$ The study of Queer activisms in the four "great cities" has been advantageous for furthering scholarly understanding of LGBT intersectionality in political participation. For instance, several works studying the activisms LGBT people of color (PoC) take place in the four "great cities" (Ordona|2000, Ramirez|2003. Ramirez-Valles, Kuhns, Vazquez \& Benjamin 2014).

${ }^{8}$ Notwithstanding the importance of gay villages as spaces for Queer activism, many analyses examine the exclusions produced by gay villages, paying particular attention on how Whiteness and masculinity both facilitate a gay urban politics of belonging that can establish within-group social hierarchies. For instance, racial exclusions have been traced in the gay villages of Manhattan, San Francisco, and Chicago (Ghaziani 2015, Rosenberg 2016, Stewart-Winter 2015). In addition to the exclusionary nature of gay enclaves in the large cities, gentrification may also reduce political participation among Queer PoC in these areas. For example, scholarship considering the impact of "White return" to large urban centres finds that White-in migration to majority Black communities erodes social capital, resulting in the political demobilization of African Americans (Newman et al. 2016). The impact of gentrification in large cities ought to be especially felt by PoC with LGBT identities, for whom Queer spaces are important locations for the generation of social capital (Doan \& Higgins 2011). 


\subsection{Small City, Suburban, and Exurban Queer Activisms}

A burgeoning scholarship on LGBT placemaking suggests that many of the more "urbane" activist ideals are not applicable to small cities (Brown 2008), suburban areas (Bain \& Podmore 2021), or exurban/rural areas (Gray 2009). As Gray (2009) notes, an emphasis on "coming out" and being visible in public spaces - a factor often used to mobilize the collective capacity of the early gay liberation movement in the "great" cities such as New York City (Kissack 1995) - cannot be directly adapted to non-urban contexts where LGBT individuals are less numerous, civic space is more limited, and community leaders and organizations are less tolerant.

Despite the apparent death of civic space for LGBT individuals to come together and form a "critical mass" (Tarrow 2011) in geographic contexts beyond large cities, however, it is not the case that large cities have a monopoly on Queer activism. Small(er) cities have hardly featured in the empirical inquiry of Queer activism. Yet, they still provide a useful context for furthering our understanding of Queer activism in areas of varying size with the hyperlocal sexual identity cultures which they foster (Brown-Saracino 2018). Though small cities lack the gay enclaves, villages, and "gayborhoods" typical of the four "great" cities, many nonetheless possess Queer spaces, including local gay bars. As is the case with Queer space in the "great cities," small-city gay bars may likewise function as crucial sub-cultural amenities in that they engender and sustain ties between individuals with LGBT identities, increase in-group affection and attachment, which can facilitate more opportunities for organizational development and LGBT events (Mattson 2020).9

Moving beyond the city, individuals with LGBT identities residing in suburban areas face a number of barriers to participation that exist as a function of place, including the unevenness of local resource landscapes, the dearth of political opportunity structures, and poor inter-organizational relations (Bain \& Podmore 2021). For instance, LGBT indi-

\footnotetext{
${ }^{9}$ While Queer spaces in large cities tend to be White and male dominated, qualitative evidence suggests that gay bars in smaller cities are at least as ethnoracially diverse as the areas in which they are situated (Mattson 2020).
} 
viduals living in suburban areas may choose not to participate in events in the downtown areas of large cities simply because they are too far away, and transportation is either lacking or too expensive. Civic leaders in suburban areas may also be less supportive of Queer activism than those in urban areas (McGirr 2015), meaning that LGBT residents of suburban areas lack the social infrastructure necessary to hold pride events.This is significant as both experimental and qualitative evidence highlight the causal impact of pride events in liberalising public attitudes towards the LGBT community (Ayoub et al. 2021). Nonetheless, in suburban areas where civic leaders are encouraging of Queer activism, the political opportunity structure for LGBT participation is much more robust, leading to the development of local LGBT friendly political structures which focus on providing spaces for LGBT individuals that enhance opportunities for intragroup contact and mobilization (Bain \& Podmore 2021).

Lastly, evidence suggests that individuals with LGBT identities living in rural areas are particularly vulnerable to nonparticipation. It is difficult, for example, to mobilize LGBT individuals living in rural communities where LGBT populations are much less dense, meaning that LGBT individuals in rural communities have fewer opportunities for intragroup contact and organization (Gray 2009). As is the case with some suburban areas, financial contributions to LGBT-friendly political infrastructure are lacking from community leaders in rural areas, who often tend to be more religious and politically conservative than those in urban areas (Drumheller \& McQuay 2010). Furthermore, while Queer visibility plays an important role in LGBT activism in urban areas, visibility is often not a viable pathway for those living in rural areas to become politically active, as being openly Queer in a rural community can lead to more discrimination and isolation (Bell \& Valentine 1995, Gray 2009). In this way, being open in one's own community may actually have downwind effects on LGBT participation in rural areas, since robust self-esteem is necessary for participation in contentious politics (McClendon|2014). 


\section{Current Study \& Hypotheses}

In sum, the claim that urbanicity is highly conducive to LGBT political participation requires at least three kinds of empirical evidence. In the first instance, individuals with LGBT identities should have a high propensity to be politically engaged in order to further their rational group interests (Olson 1965). Furthermore, those with LGBT identities should have a greater propensity than cisgender/straight individuals to become politically active, given that the potential benefits for marginalized groups are often much greater than those for nonmarginalized groups.

H1a: LGBT individuals will exhibit higher rates of political participation than non-LGBT individuals.

Notwithstanding the gap in participation between LGBT-identifying individuals and cisgender/straight individuals, however, it is also important to be aware that there are likely to be asymmetric outcomes in levels of participation among different substrata of the LGBT respondents. LGBT identification is just one social identity, among many competing and often cross-pressurising identities (Brader et al.|2013, Turnbull-Dugarte 2020), that individuals may adopt. The presence of multiple sources of marginality (Crenshaw 1993) or of competing identity influences may inhibit political participation (Bergersen et al. 2018). For instance, we might expect to observe noteworthy, within-group differences in participation when contrasting on race and gender, given that racial and patriarchal hierarchies constrain participation for people of color $(\mathrm{PoC})$ and individuals who identify as female. These developments lead us to state our first hypothesis as:

H1b: There will be noteworthy within-group differences in levels participation by race and sex. 
While there is already some evidence of a sexuality and gender identity "gap" in political participation within advanced Western liberal democracies (Turnbull-Dugarte \& Townsley 2020, Edelman 1993, Sherrill \& Flores 2014, Page 2018), there is less evidence on the role of geographic context, and specifically, urban residence, in shaping higher rates of political participation among individuals with LGBT identities. Rather, most studies include a dichotomous control for urban/non urban residence (Turnbull-Dugarte \& Townsley 2020), or simply do not include one at all (Lewis, Rogers \& Sherrill|2011, Perez 2014). These studies do not provide a robust approximation of how patterns of LGBT participation vary across the rural-urban interface. As a result, there is a need for a more nuanced test of the role of geographic context in shaping political participation among individuals with LGBT identities. Moreover, given the plethora of urban-rural classification schemes within the extant scholarship (Nemerever \& Rogers 2021), it is also important that the hypothetical relationships between LGBT identity, urbanicity, and political participation hold across a variety of subjective and objective definitions of "urban" and "rural". These developments lead us to state our second hypothesis as:

H2: LGBT individuals living in urban area will exhibit higher rates of political participation than LGBT individuals living in non-urban areas. These relationships will be robust to subjective and objective measures of urbanicity.

Lastly, even if we find that LGBT individuals who live in urban areas are more likely to be politically engaged than LGBT individuals living in non-urban areas, it is not our claim that urban residence is directly engendering participation. Rather, our expectation is that a high concentration of LGBT individuals within a geographically-bounded space will generate greater opportunities for intragroup contact and interactions focused on shared group interests, thus leading to a greater possibility for political action (Enos|2017. Putnam 1966, Tarrow 2011, Tavares \& Carr 2016). Given that LGBT populations tend to 
be clustered within America's largest cities (Conron et al. 2020), there is reason to expect that these hypothetical relationships are especially salient for LGBT individuals living in larger metro areas of the U.S. Our third hypothesis is thus stated as:

H3: LGBT political participation will be conditioned by the metro area percentage of LGBT residents, such that LGBT individuals living in areas with a higher percentage of LGBT residents will exhibit higher rates of political participation.

\section{Data \& Methods}

\subsection{Data}

To test these hypotheses, we leverage data from the 2020 Cooperative Election Study (CES). The CES is a nationally-representative online-based survey of $\mathrm{N}=61,563$ adults living in any of the 48 contiguous US states, as well Alaska or Hawaii. The survey was administered by the polling company YouGov, and consisted of a 20-minute pre-election wave fielded in October 2020, and a 10-minute post-election wave fielded in November 2020. The very large sample is uniquely advantageous as it allows us to explore patterns of LGBT participation while both disaggregating by small-area geography and considering wihin-group intersectional variation among LGBT individuals.

\subsection{Dependent \& independent variable operationalisation}

Our outcome variable of interest is political participation. Given the propensity of survey respondents to over-report electoral participation - social norms regarding the desirability of electoral participation incentivise individuals to claim they voted in elections even if they did not - we focus our empirical assessment on non-electoral forms of participation in the democratic process. The CES asks respondents if, during the last twelve months, 
Table 1: Distribution of respondents on self-reported participation measures

\begin{tabular}{lcc}
\hline Political activity & $\begin{array}{c}\text { Participated } \\
(\%)\end{array}$ & $\begin{array}{c}\text { Did not participate } \\
(\%)\end{array}$ \\
\hline Voted & 93.34 & 6.66 \\
Attended political meeting & 8.04 & 91.96 \\
Volunteered in political campaign & 5.07 & 94.83 \\
Contacted politician/representative & 23.15 & 76.85 \\
Put up a political sign & 18.78 & 81.22 \\
Took part in political protest & 8.25 & 91.75 \\
Donated to a political campaign & 28.30 & 71.70 \\
\hline Note: Weighted percentages. & &
\end{tabular}

Note: Weighted percentages.

they have engaged in different forms of political activity. These forms of participation, and the distribution of responses to these different activities, are summarised in Table 1 Other than (self-reported) participation in elections, those forms of activity that are most prevalent among respondents include making campaign donations and making contact with candidates or representatives. Of note is that those forms of activity that come with higher costs - e.g. volunteering free labour and time for a campaign - are far less common. For parsimony, we collapse responses to the political participation items, with the exception of self-reported voting behaviour, into a single political participation index. Principal component factor analysis demonstrates that the participation items load onto a single dimension producing a reliable (Cronbach's $\alpha=.70)$ indicator of overall participation. Our ParticipationIndex is scaled 0-1 with higher values indicating increased propensity to engage in non-electoral forms of political participation. Given that the individual participation items may also come with asymmetric costs for individuals, we also estimate item-specific models for robustness.

To stratify our sample based on sexual and gender identity, we rely on CES respondents' self-identification as a lesbian, gay, bisexual or transgender person. The 2020 CES does not contain a single measure of LGBT identity. For sexual identity, the CES asks a respondent whether they identify as heterosexual, lesbian, gay bisexual, or "other." While the item for gender identity is a dichotomous measure that asks a respondent whether 
they are transgender $(1=$ "yes," $0=$ "no"). Using these items, we construct a dichotomous measure of LGBT identity where respondents who identify as lesbian, gay, bisexual, and trans are coded as 10 and cisgender/straight respondents as 0 . Overall, $10.51 \%$ of the (weighted) ${ }^{11}$ sample identifies as LGBT.

To test H2, and following the recommendations of Nemerever \& Rogers (2021), we operationalize urbanicity via alternative subjective and objective approaches. Our subjective measure relies on CES respondent's claims where their place of residence fall on a four-point categorical measure: 1 (City), 2 (Suburbia), 3 (Town), 4 (Rural area/Country). However, since self-identification of urbanicity often to not correlate with objective placebased classifications (Nemerever \& Rogers 2021), we also rely on objective measures on place-based indicators. Concretely we utilise the rural-urban continuum codes (RUCC) provided by the US Department of Agriculture's Economic Research Service. ${ }^{12}$ The RUUC variable is a 9-point measure that categorically indicates the urbanicity of areas based on the population size of their metro area, degree of urbanization, and adjacency to a metro area (Nemerever \& Rogers 2021) and ranges from "Metro area with 1 million inhabitants or more" to "Non-adjacent metro area with less than 2,500 inhabitants".

Testing H3, which seeks to isolate the mechanism that drives divergent levels of participation among LGBT individuals in urban and rural settings, we leverage LGBT population estimates provided by the William's Institute (Conron et al. 2020). The William's Institute estimates facilitate data on the proportion of the LGBT population among the

\footnotetext{
${ }^{10}$ Though the measure for sexual identity includes an "other" category for respondents who are not heterosexual but also do not identify as LGB, we nonetheless do not code these respondents as 1 primarily due to concerns relating to the validity of our multilevel model. The contextual level data we leverage to test for the moderating effects of intragroup contact and mobilization only includes estimates for LGBT individuals, and not those who might have chosen "other" in the CES including, presumably, Queer and asexual individuals. Including these respondents in our sample while specifying a multilevel model using the metro-level LGBT population estimates might therefore introduce greater unobserved heterogeneity when contrasting on our gender/sexual identity variable. In any event, even if we did have reliable metrolevel estimates for queer, asexual, and other sexual minority populations, the binning of non-heterosexual, non-LGB respondents into the "other" category in the CES sexual identity measure does not allow us to identify respondents who might identity as such.

${ }^{11}$ The raw number of observations is 7,104 which equates to $11.39 \%$ of the unweighted sample.

${ }^{12}$ Available at: https ://www.ers.usda.gov/data-products/rural-urban-continuum-codes/
} 
US' largest metropolitan statistical areas. The range of these estimates runs from 3.3\% (e.g. Raleigh, North Carolina or Pittsburgh, Pennsylvania) to 6.7\% (San Francisco, California).

\subsection{Covariates}

Our models include individual-level control variables. First, the model conditions on gender, age (and age squared), race, and immigration/citizenship status in the US. Given that these variables are "unmoved movers" (Berelson et al. 1954, Campbell et al. 1960), we can assume that there inclusion in the model does not introduce post-treatment bias (Acharya et al. 2016) in the assessment of the independent effect of LGBT identification on our outcome measure. Gender is a dichotomous measure indicating those who identify as female (1) or male (0). Age operationalised continuously (years). Race is a 6-point categorical variable identifying respondents who identify as: white (baseline), Black, Hispanic, Asian, Multi-racial, or as any other race. Finally, immigration/citizenship status is operationalised via a five-point indicator that stratifies individuals who are, at least, third generation American (baseline), those whose parents were born in the US (second generation American), those who parents were not born in the US (first generation American), as well as those who were not born in the US and have, or have not, gained naturalised citizenship.

\subsection{Empirical approach}

Empirically, we test $\mathrm{H} 1$ by estimating a linear regression model (OLS) regressing our Participation Index on LGBT status whilst controlling for our specified vector of covariates. To assess H2, we replicate the main model specification to include a multiplicative interaction term between LGBT identification and urbanicity using, independently, our subjective and objective measures of the urban-rural continuum. Finally, in our assessment 
of the mechanisms underlying the divergence in LGBT participation between urban and rural settings, we estimate a hierarchical model in which we assess the moderating effect of LGBT population density among the largest metro areas.

\section{Results}

\subsection{Sexuality gap in political participation}

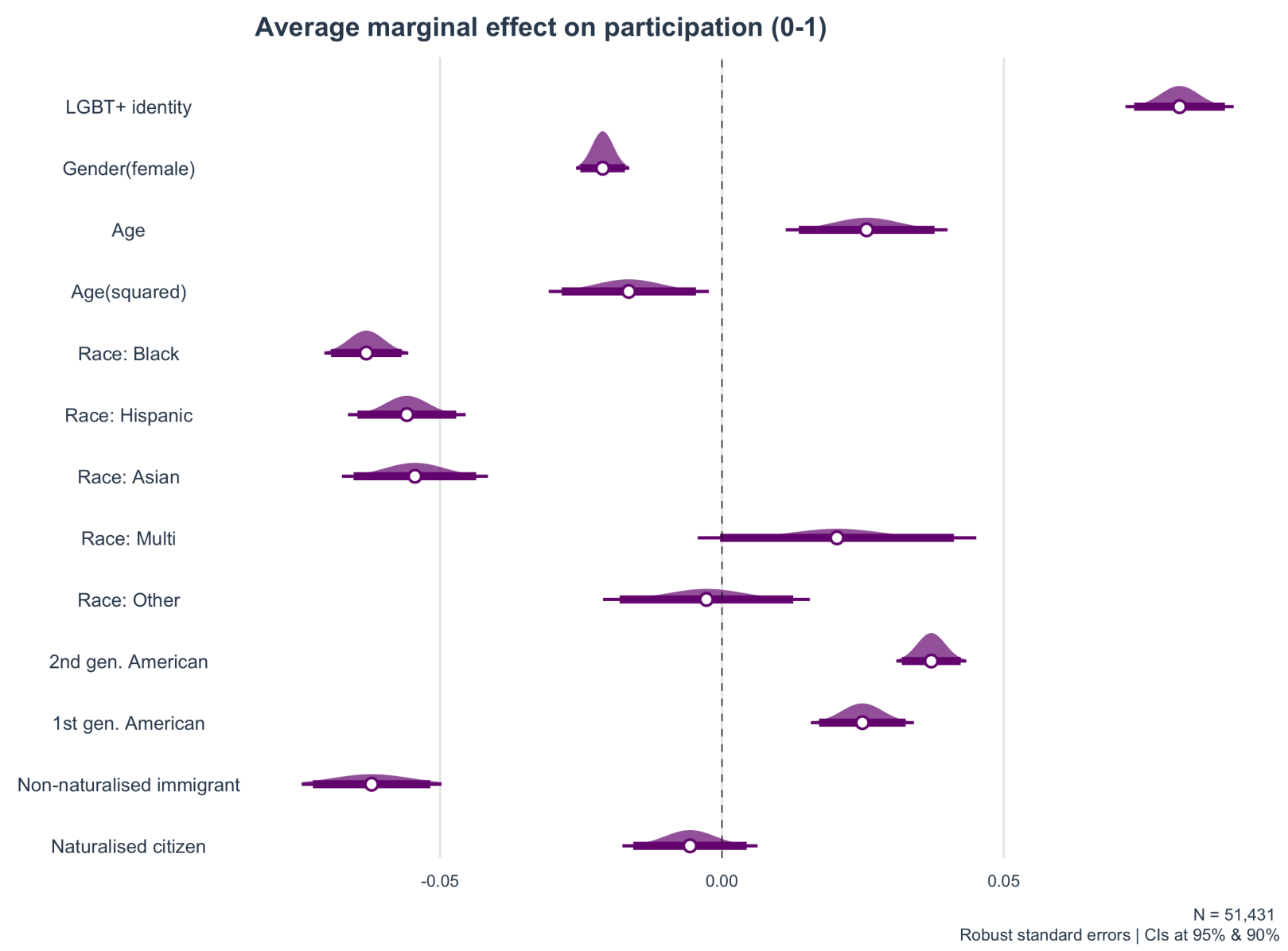

Figure 1: Modelling who participates in politics

To test H1, we begin by modelling the determinants of political participation. Figure 1 reports the effects of LGBT status on our participation index whilst conditioning on a vector of covariates that we can confidently assume are causally anterior to LGBT iden- 
tification. In line with $\mathrm{H} 1$ and previous literature on the the sexuality gap in electoral and non-electoral political participation, we observe a substantive and significant positive effect on LGBT identification. Vis-à-vis their heterosexual peers, LGBT individuals are significantly more prone to engage in political activity $(\beta=.08 \| t=23.85)$. Given a mean participation index value in the sample of $.167(\sigma=.228)$, a coefficient of .08 equates to a $47.9 \%$ change in the mean ( $35 \%$ of a standard deviation). In comparison to the divergence between a number of canonically identified variables of political participation (e.g. gender or race) we find that the gap between LGBT and non-LGBT individuals is of a superior magnitude. The variance in participation between men and women for example is substantively smaller $(\beta=-.02 \| t=-11.11)$, whereas between white and black individuals the divergence is more similar at $-.06(t=-20.12)$.

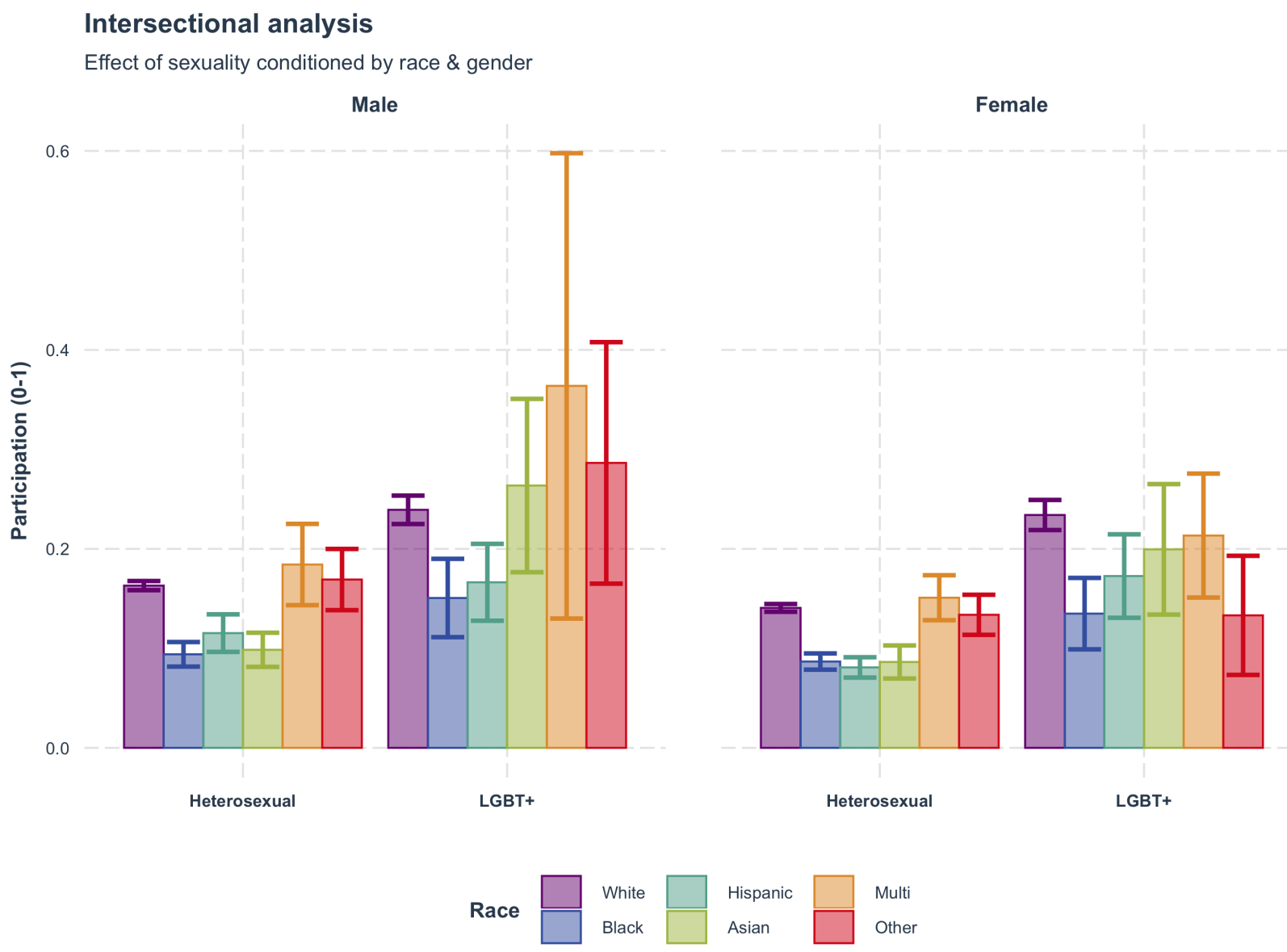

Figure 2: Within sexuality-group variation by sex and race 
Does the increased levels of participation among LGBT individuals hold among different subsections within the LGBT population? As argued by Perrella et al. (2019) and Turnbull-Dugarte (2020), Turnbull-Dugarte (2020), the LGBT community is not a monolith and, within the collective, intersectional processes of discrimination based on sex or race - to give just two examples - have the potential to produce asymmetric outcomes for different social strata. Understanding the potential asymmetric effects of LGBT identity on political participation is important as within the LGBT community racial and patriarchal hierarchies may constrain the participation-inducing effect of non-heterosexual or cisgender identification.

Testing for within-group variation in political participation among different LGBT social strata, we observe that the positive effects of LGBT identity are not unique to either white respondents or to men. In Figure 2 we replicate the model specification reported in Figure 11 with the addition of a three-way multiplicative interaction term between LGBT identity, gender and race. The left-hand panel reports the predicted participation scores for men of different racial identities who identify as heterosexual or LGBT. Across all racebased identity categories, the participation scores are higher for LGBT men than they are for heterosexual cisgender men. The marginal effect of sexuality amongst men ranges from $.04(t=1.98)$ in the case of Hispanic men to .17 in the case of Asian men $(t=3.87)$. For those men who identify as Multi-racial or "other" the LGBT coefficient remains positively signed (respectively: $\beta=.19$ and $\beta=.10$ ) although it is not indistinguishable from zero. These null results are, however, which is likely the product of the smaller number of observations in these racial categories.

Turning towards the sexuality gap amongst women from different racial groups (righthand panel Figure 2), we find similar, robust evidence that the increased political participation among LGBT women is not conditioned by racial stratum. Across all racial categories with the exception of those who report to be "other", LGBT women are significantly more participative than cisgender heterosexual women of the same race. As 
in the case of men, the largest sexuality effect is observed in the case of Asian women ( $\beta=.12 \| t=3.60)$. Importantly, sexuality appears to lead to convergence between the participation levels between men and women. Whilst in the case of cisgender heterosexuals; White, Black, and Hispanic men are all significantly more inclined to be engaged in politics than women of the same race, the same is not true of LGBT individuals. The differences between LGBT and LGBT women of the same race are insignificant implying that the increased positive associated between LGBT identity and participation for women has an equalising effect that places the mean level of participation among LGBT women on a symmetrical level to that of LGBT men.

\subsubsection{Robustness test: asymmetric activities \& asymmetric costs}

Above we demonstrate that an LGBT gap is present in political participation and that this gap is robust to various tests of conditionally based on the intersectional heterogeneity within the US' LGBT population. The results above model the effect of LGBT status on our participation index which collates individuals' responses to the battery of participation items detailed in Table 1 into a single factor. As a robustness test, we model the variation in participation associated with LGBT identities across these individual items separately as a means of considering that different forms of political participation are likely to induce varied levels of "costs" for voters.

Across the different items that constitute our Participation Index, we observe significant effects. We can be confident, therefore, that the significant positive effects on participation associated with LGBT identification are not the result of any one influential particiaption item.

\subsection{The sexuality gap and the city}

We now consider to what extent the increased levels of political participation among individuals who identify as LGBT is unique to urban-dwelling individuals who are most 


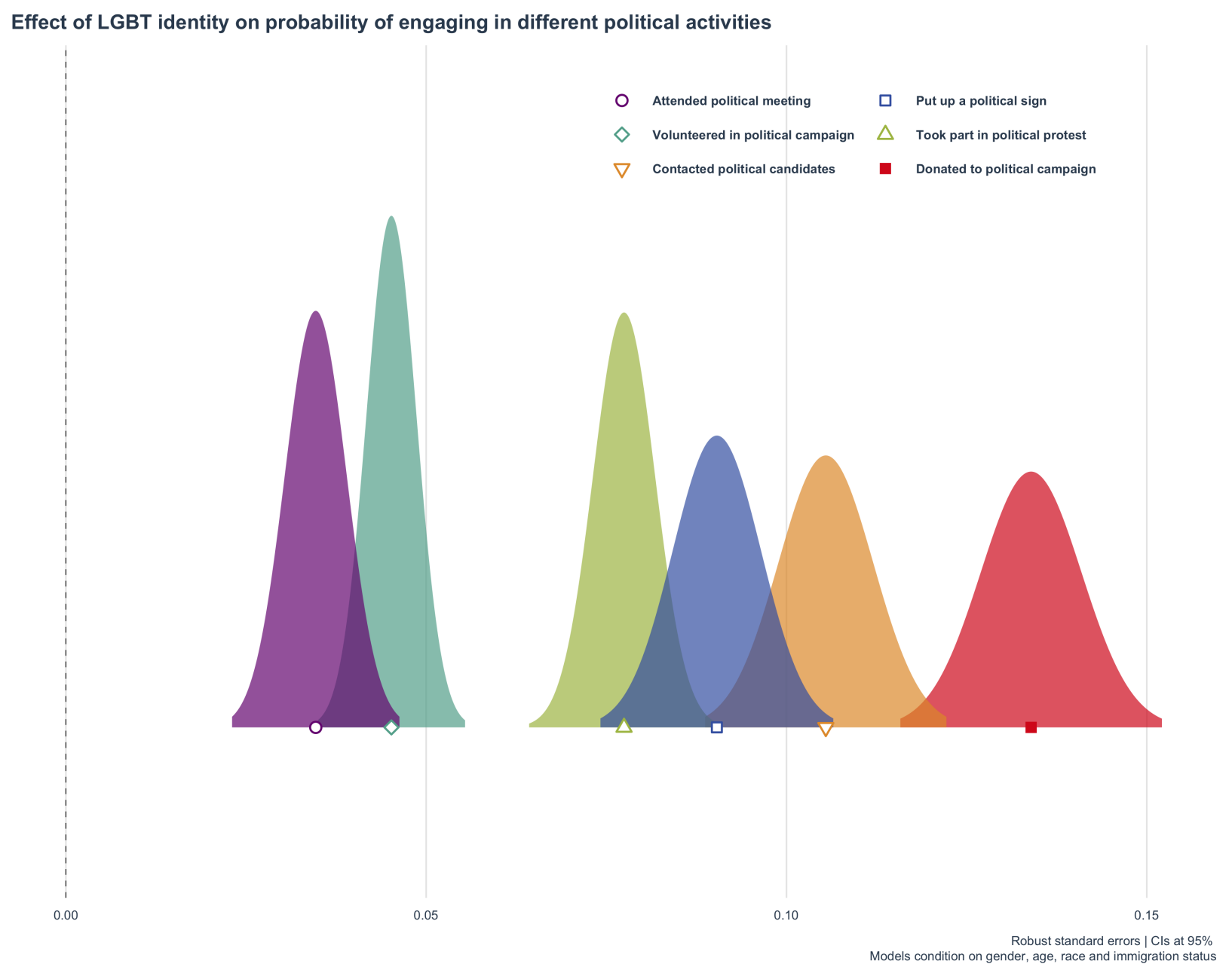

Figure 3: LGBT gap across independent participation items

susceptible to intragroup mobilisation via the geographic propinquity to LGBT activism.

In order to test for the conditionality of the sexuality gap across urban and rural settings, we model the effect of LGBT identity conditioned by two distinct measures or urbanicity. In the left-hand panel of Figure 4 we condition sexual identity status on subjective measures of respondents' urban/rural location. In the right-hand panel we condition LGBT identification on objective measures based on the rural urban continuity codes (RUUC).

Considering first subjective measures of urbanicity, we find strong support for $\mathrm{H} 2$ : the gap between LGBT and heterosexual cisgender individuals who report to live in cities ( $\beta=.10 \| t=11.94)$ is significantly larger than the sexuality gap observed among those 
Subjective urbanicity

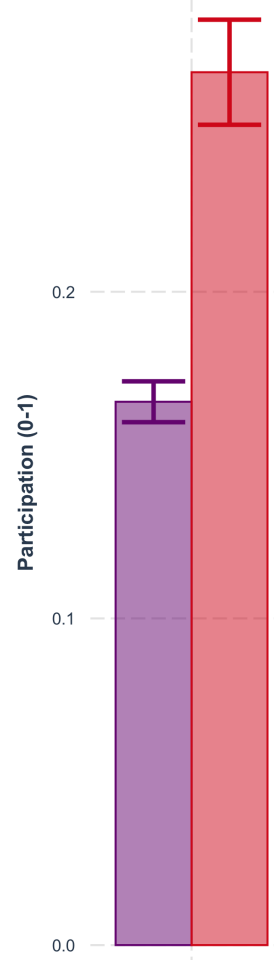

City

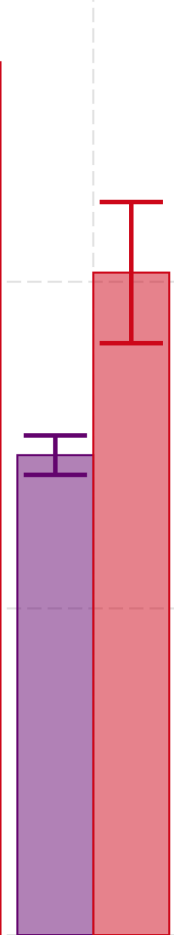

Suburbia

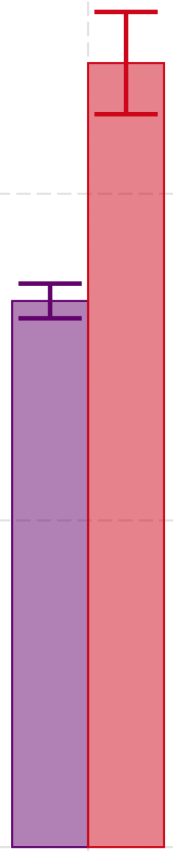

Town

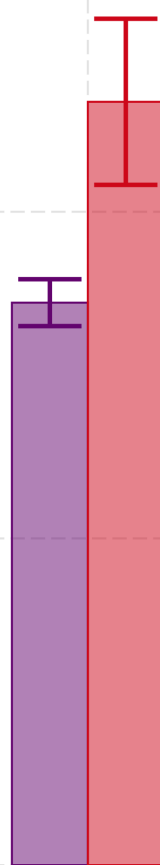

Rural area/Country
Objective urbanicity

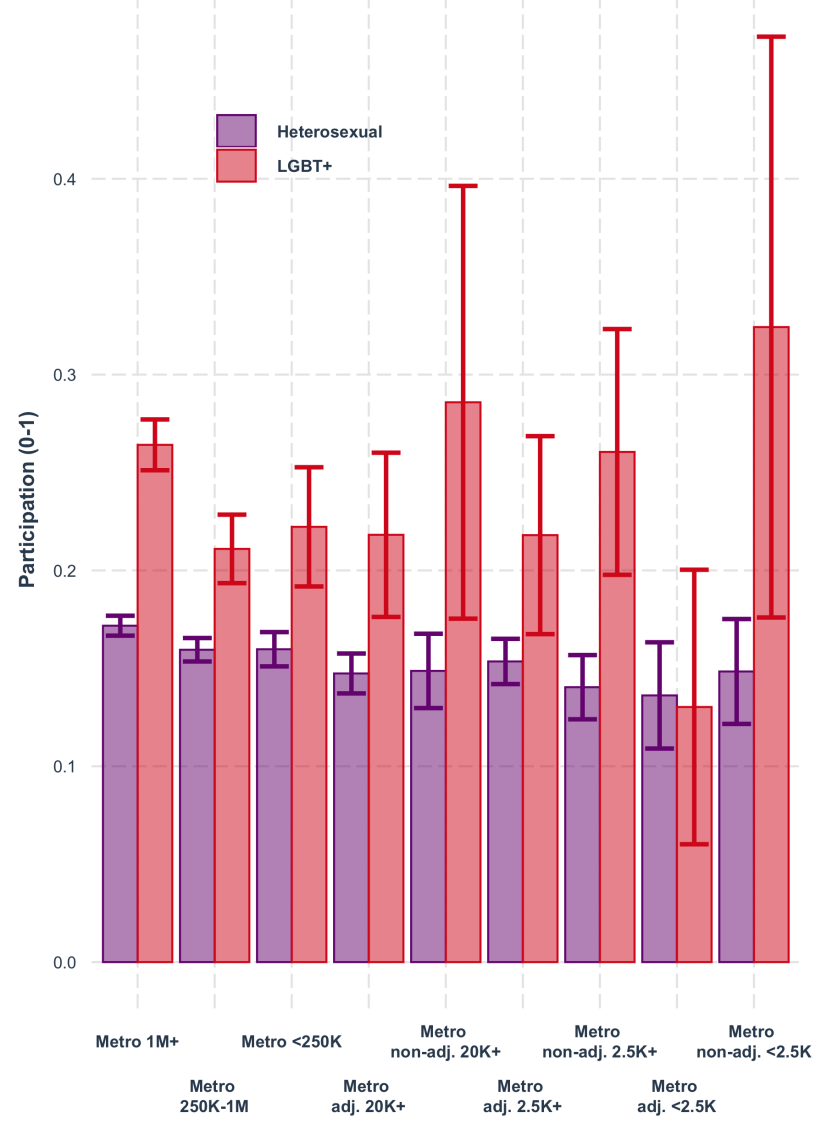

Figure 4: LGBT vs heterosexual participation across varying levels of urbanicity

who report living in the suburbs $(\beta=.07 \| t=9.02)$, towns $(\beta=.06 \| t=4.66)$ or in rural areas $(\beta=.06 \| t=4.99)$. Across different values of subjective urbanicity LGBT individuals are more politically active but their increased propensity to participate is not evenly distributed across varying levels of (self-reported) location within the urban-rural divide.

Turning to consider the moderating role of objective placement on urban-rural continuum via the RUUC values (right-hand panel Figure 4), we see largely consistent results. First let us came of the difference between respondents living in metropolitan areas with more than 1 million inhabitants with those living in metropolitan areas with less than 250,000 inhabitants. The conditional effect of LGBT identity in the former is .09 $(t=4.66)$ 
whereas is is smaller at $.06(t=3.95)$ in the latter: whilst in both metropolitan areas types LGBTs are more political engaged vis-à-vis cisgender heterosexuals, the magnitude of the divergence decreases in less urban areas. Amongst the more rural areas (e.g. those RUUC areas that are Metro-adjacent and non-adjacent with populations of less than 2,500 individuals) isolating variation in participation associated with LGBT identity becomes, statistically, more challenging as a smaller number of LGBT observations in these areas reduces the power available to effectively identify effects that are distinguishable from zero.

\subsection{Intragroup mobilisation within the city}

Our theoretical argument draws a link between increased urbanicity and a higher level of divergence between LGBT and non-LGBT political engagement, positing that increased propinquity to more LGBT individuals, LGBT "culture" and, as a result, LGBT activism and political mobilisation, will engender increased political participation. Should the increased propensity of LGBT individuals to participate in the democratic process be the result of intragroup mobilisation efforts rather than the product of some spurious relationship associated with urbanicity, we would expect there to be variation in LGBT participation between metropolitan areas with varying LGBT population sizes. In other words, if increased LGBT engagement in political activity is the product of the mobilisation processes that take place in localities where intragroup contact and interaction is likely to be highest, then we would expect the increased political engagement among LGBT respondents to be significantly greater in those metropolitan areas that are more densely inhabited by other LGBT individuals.

Relying on LGBT populations as an instrumental measure of the propensity for intragroup contact between LGBT persons, we estimate a multilevel model taking metropolitan area as the level-2 hierarchical unit of analysis, and include a multiplicative interaction term between individual-level LGBT identity and metropolitan-level LGBT population 


\section{Testing intragroup mobilisation theory}

Effect of sexuality conditioned by LGBT+ population density

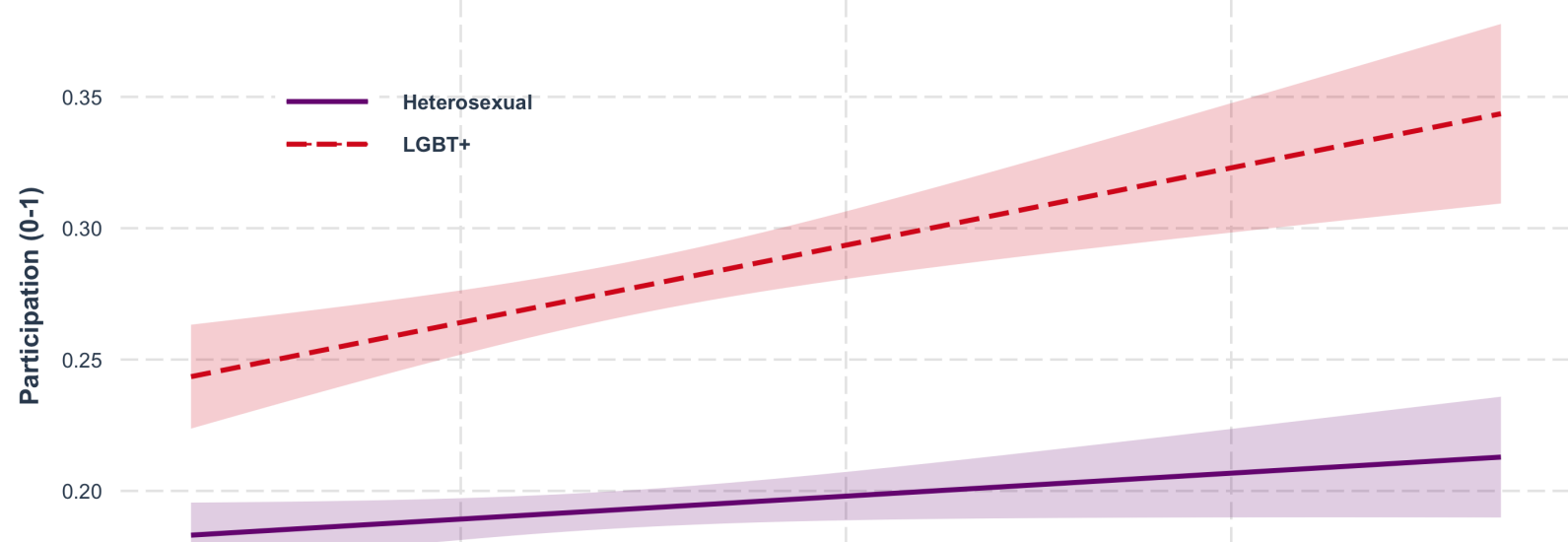

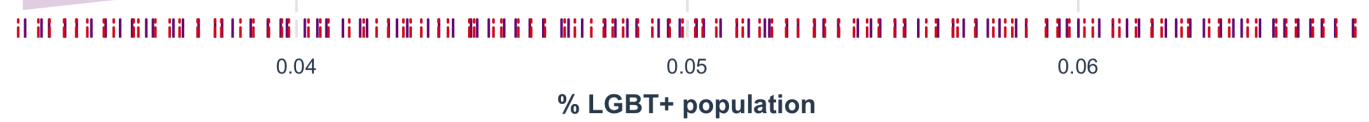

Intragroup contact test conditioned by gender

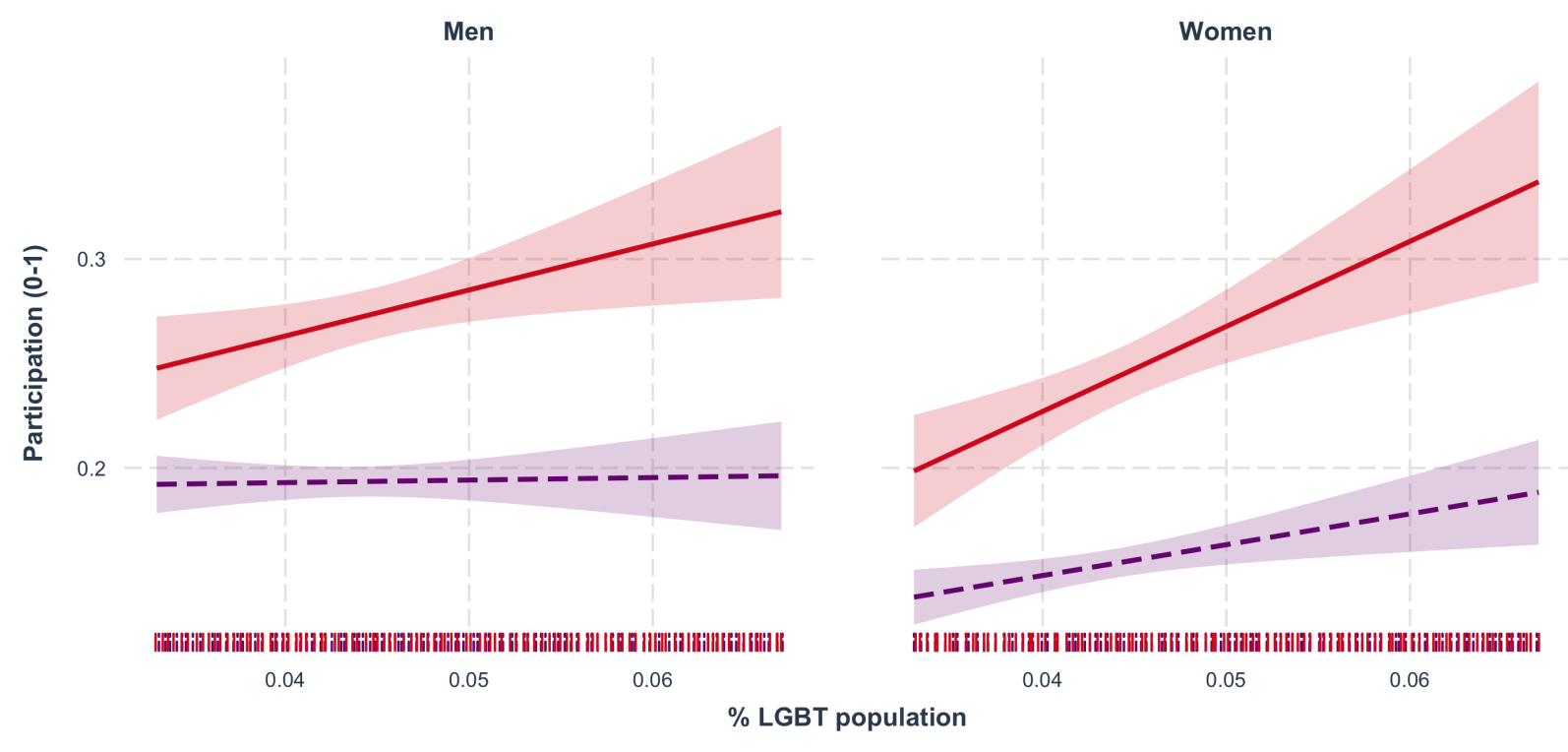

Figure 5: Testing for the intragroup contact mechanism

density. In addition to the individual-level covariates, in the multi-level model testing $\mathrm{H} 3$ we also include a control for the population density of non-white individuals. One might expect metropolitan areas with a large LGBT population to also be more ethnically diverse (i.e. have a greater proportion of non-white residents). Testing for this (see appendix Figure A1 shows a small, yet significant, correlation. Controlling for the proportion of ethnic diversity, therefore, is important in order to isolate the effect of LGBT 
population density.

Figure 5 reports the marginal effect of LGBT status across varying levels of LGBT population density in the US's 55 largest metropolitan areas among all respondents (upper panel) as well as specifically for men (lower left) and women (lower right). The figure includes an overlaid rugplot to demonstrate the distribution of observations across different moderator values.

The results of our multi-level interaction models indicate that intragroup interaction matters when it comes to understanding increased LGBT participation. Among the US' 55 largest cities, we find that increases in the percentage of the LGBT population significantly increases the participation index values for LGBT individuals whilst exhibiting no effect of substance or significance on participation scores for heterosexuals. In short: in those urban settings where LGBT individuals are more likely to be exposed to intragroup mobilisation efforts, LGBTs are more inclined to participate in the democratic process which, subsequently, increases the disparity in levels of participation between LGBT and non-LGBT respondents. Importantly, disaggregating our Participation Index measure into its composite parts does not alter our conclusions. With the exception of the $\operatorname{Pr}$ (Putting up a political sign), there is a significant interaction effect between LGBT identification and LGBT population density on the probability of engaging in all other political activities that we consider (see appendix Figure A2).

The significant moderating effect of LGBT population density is observed to be active amongst men and women. The lower panels in Figure 5 report the output of three-way interactions between LGBT status, gender, and LGBT population density. The significant and positive association between LGBT population density and LGBT participation is observed in the case of both GBT men and LBT women. The incremental effect for women is, however, more substantive leading to a convergence in the predicted participation index scores between GBT and LBT women among respondents that fall on the higher end of the LGBT population density distribution. 
As a potential placebo test, we replicate the specification of our multi-level model but interact LGBT identification with the non-white population as opposed to the LGBT population. Should our intragroup theory argument hold, we would expect this "placebo" moderator to report insignificant effects: i.e. the sexuality gap should not be any more pronounced in those locations where the non-white population is greatest. The results of this robustness test (appendix Figure A3) confirm our expectations, reporting no significant variation in the divergence between LGBT and non-LGBT individuals' participation across varying concentrations of non-white populations. We interpret these findings as evidential support for the argument that intragroup mobilisation is an important explanatory mechanism that helps us understand i) under what conditions the sexuality gap in political behaviour manifests and, ii) what explains the divergent levels of LGBT participation between urban and rural ecologies.

\section{Discussion}

Active participation in the electoral and nonelectoral processes is crucially important for those who identify as LGBT, since participation functions as a means of maximizing inclusiveness, and also aids the contribution of policy output from elected officials to further their utility-maximizing welfare (Turnbull-Dugarte \& Townsley 2020). While an emergent scholarship finds a consistent relationship between LGBT identity and robust levels of electoral and nonelectoral participation (Egan, Edelman \& Sherrill 2009 , Perez 2014. \begin{tabular}{l|l|l|l|l|}
\hline Swank 2019, Swank \& Fahs 2013, Turnbull-Dugarte \& Townsley 2020), consideration of
\end{tabular} the role of urbanicity in sharping LGBT participation has been notably absent. As we have argued throughout this paper, this omission is noteworthy given the important links between urbanicity and political participation (Castells 1983) more broadly, as well as the

important relationship between urbanicity and LGBT activism (Ayoub et al. 2021). Consistent with the "critical mass" model of participation (Tarrow 2011), we posited that a 
high concentration of individuals within a geographically bounded space would increase the chances for intragroup contact (Enos|2017). When individuals come into contact, they might become likely to share common concerns, thus giving them a greater propensity to organize for political action (Tavares \& Carr 2016). Given that $88.3 \%$ of individuals with an LGBT identity live in an urban area (Badgett et al. 2019), there was reason to expect that urbanicity was therefore an especially important concomitant of LGBT participation.

The present study represents an important step in attempting to fill this gap in the literature. In this paper, we have explored whether there continues to be a noteworthy sexual and gender identity "gap" in political participation in the United States, whereby LGBT individuals exhibit higher rates of participation in democratic activities than cisgender/straight individuals (H1a). Moreover, we have examined whether there are notable within-group differences in levels of participation by race and sex (H1b). We have also explored how patterns of LGBT participation vary across the urban-rural interface, and whether these findings held across subjective and objective definitions of rurality (Nemerever \& Rogers 2021) (H2). Lastly, we have explored whether intragroup contact and mobilization fosters robust LGBT participation in America's largest metro areas (H3). We addressed these hypotheses using data from the 2020 CES.

Our paper contributes to the existing scholarship in three important ways. First, we find additional evidence for a sexual and identity "gap" in political participation in the United States ((Swank \& Fahs 2013, Perez 2014), albeit leveraging a much larger sample than any of these prior studies. On average, LGBT-identifying individuals are more likely to participate than cisgender/straight individuals in a variety of nonelectoral political activities. Importantly, we also find that levels of participation among LGBT-identifying individuals relative to those who are cisgender/straight hold among different substrata of the LGBT population. For instance, when testing for within-group participation stratified by race and gender, we observe that the effects of LGBT identity on participation are not unique to White CES respondents who identify as male. Indeed, LGBT men and women 
are significantly more likely than cisgender/straight men and women to participate in the nonelectoral process regardless of racial identities. Nevertheless, our intersectional analyses also demonstrate that processes of LGBT-discrimination based on race and sex produces asymmetric outcomes in levels of participation, particularly for Queer people color (PoC). For example, White women who identify as LGBT exhibit the highest rates of participation compared to women of any other race, while White men who identify as LGBT exhibit higher rates of participation than Black and Hispanic LGBT-identifying men. It is important to draw attention to these findings given that the broader LGBT community is not monolithic male (Perrella et al.2019, Turnbull-Dugarte 2020). Consideration of these asymmetric effects through race and gender is also important because they provide further evidence that racial and patriarchal hierarchies may continue to constrain participation for PoC who identify as LGBT.

Second, by examining of how patterns of LGBT participation vary across the urbanrural continuum, we now have a better approximation of the role of geographic context (and especially urbanicity) in shaping Queer activisms. Prior studies of LGBT participation included a dichotomous measure for urban/non-urban residence (Turnbull-Dugarte \& Townsley 2020), or simply did not include one at all (Lewis, Rogers \& Sherrill 2011. Perez 2014). However, we posited that collapsing non-urban geographic contexts into a dichotomous measure of "urban/nonurban" was problematic, as it ignored a large scholarship that speaks to the existence of Queer activism in smaller or "ordinary" cities, suburban areas, and exurban areas of the U.S. Consequently, it was not altogether clear whether urban areas were more conducive to LGBT participation than these smaller geographic locales. As such, there was a need for a more nuanced examination of the role of geographic context in shaping political participation among LGBT-identifying individuals that these prior studies.

In our test of how LGBT participation varies across the urban-rural interface, we found that subjective measures of urbanicity - i.e., individuals who self-reported living a city - 
were important predictors of participation, thus lending weight to H2. Given the many ways of defining and measuring the rural-urban continuum in political science (Nemerever \& Rogers (2021), it was also important to test whether the relationships between LGBT identity, urbanicity, and political participation were robust to objective urban-rural classification schema. When using the RUCC classification scheme, we found that LGBT individuals living in metro areas with greater than a million residents exhibited high rates of participation relative to those in smaller metro areas, as well as those residing in smaller communities that were adjacent to a metro area, thus lending further weight to $\mathbf{H 2}$.

Still, we encountered problems related to statistical power and significance when it came gauging to LGBT participation in metro non-adjacent counties with a population of less than twenty thousand residents. Therefore, while we find some evidence that city residence is particularly conducive to greater participation among LGBT individuals, it is important to qualify that the low number of LGBT-identifying survey respondents living in smaller geographic locales makes comparison across the urban-rural continuum somewhat difficult. Still, that we find subjective measures of urbanicity and being resident of a metro area with a population greater than 1 million people to be highly conducive to participation speaks to the importance of urban space in generating the opportunities for communication, group identity, and collective action among LGBT-identifying individuals (Tarrow 2011).

Lastly, our paper builds on the academic scholarship by providing validation of the theoretical mechanisms explaining the underlying divergence in LGBT participation across urban and non-urban contexts. To empirically test our theoretical mechanism, we leveraged contextual data on the percentage LGBT individuals living in the 55 largest metro areas of the US as an instrumental measure of intragroup contact and mobilization (Conron et al. 2020), finding that, at the individual level, LGBT participation is moderated by LGBT population density in the direction of greater participation. These results indicate that political participation among LGBT-identifying individuals is more robust in 
areas with a higher density of LGBT residents. This finding is particularly noteworthy because our instrumental approach lends empirical weight to extant models of participation within geographically bounded communities (Enos 2017). As these works indicate, it is not the case that LGBT population density directly fosters participation. Rather, a high concentration of LGBT identifying individuals creates the chances for intragroup contact, thus increasing the likelihood that individuals with common interests (i.e., LGBT individuals" utility-maximizing interests) can come together to form a "critical mass" and organize for political action (Tarrow 2011). Crucially, our instrumental moderator is also robust to controlling for metro-level ethnic heterogeneity, suggesting that the effects of LGBT population density on high rates of participation are not being influenced by the effects of other variables that are known to affect participation.

Future work may seek to expand on the identification of intragroup contact as the driving mechanism behind increases political participation among LGBT-identifying individuals. The significant moderating effects we identify in this study assume that residency within localised areas with increased LGBT populations serves as a instrumental measure of intragroup contact and exposure but the dataset we rely on does not allow us to confirm if individuals in those areas are indeed "exposed" to more LGBT activity. 


\section{References}

Abrajano, M. (2010), 'Are blacks and latinos responsible for the passage of proposition 8 ? analyzing voter attitudes on california's proposal to ban same-sex marriage in 2008', Political Research Quarterly 63(4), 922-932.

Acharya, A., Blackwell, M. \& Sen, M. (2016), 'Explaining causal findings without bias: Detecting and assessing direct effects.', American Political Science Review 110(3).

Annes, A. \& Redlin, M. (2012), 'Coming out and coming back: rural gay migration and the city', Journal of Rural Studies 28, 56-68.

Anthony, R. M. (2014), 'Urbanisation and political change in the developing world: a cross-national analysis, 1965-2010', Urban Affairs Review 50(6), 743-780.

Ayoub, P. M. \& Page, D. (2020), ‘When do opponents of gay rights mobilize? explaining political participation in times of backlash against liberalism', Political Research Quarterly 73(3), 696-713.

Ayoub, P. M., Page, D. \& Whitt, S. (2021), 'Pride amid Prejudice: The Influence of LGBT+ Rights Activism in a Socially Conservative Society', American Political Science Review 115(2), 467-485.

Badgett, M. L., Choi, S. K. \& Wilson, B. D. (2019), LGBT poverty in the United States: A study of differences between sexual orientation and gender identity groups, The Williams Institue, UCLA, Los Angeles, CA.

Bailey, R. (1999), Gay Politics, Urban Politics: Identity and Economics in the Urban Setting, Columbia University Press, New York City, NY.

Bain, A. L. \& Podmore, J. A. (2021), ‘Relocating queer: Comparing suburban lgbtqts activisms on vancouver's periphery', Urban Studies 58(7), 1500-1519. 
Becker, A. M. \& Copeland, L. (2016), ‘Networked publics: How connective social media use facilitates political consumerism among lgbt americans', Journal of Information Technology and Politics 13(1), 22-36.

Bell, D. \& Valentine, G. (1995), 'Queer country: Rural gay and lesbian lives', Journal of Rural Studies 11, 113-122.

Berelson, B., Lazarsfeld, P. F. \& McPhee, W. N. (1954), Voting: A Study of Opinion Formation in a Presidential Campaign., University o Chicago Press, Chicago.

Bergersen, M., Klar, S. \& Schmitt, E. (2018), 'Intersectionality and engagement among the lgbtq+ community', Journal of Women, Politics \& Policy 39(2), 196-219.

Bowers, M. M. \& Whitley, C. T. (2018), 'Assessing voter registration among transgender and gender non-confirming individuals', Political Behavior 42(1), 143-164.

Brader, T., Tucker, J. A. \& Therriault, A. (2013), '“cross pressure scores: An individuallevel measure of cumulative pressures arising from social group memberships', Political Behaviour 36(1), 23-51.

Brown, G. (2008), 'Urban (homo)sexualities: Ordinary cities and ordinary sexualities', Geography Compass 2(4), 1215-1231.

Brown-Saracino, J. (2018), How Places Make US: Novel LBQ Identities in Four Small Cities, University of Chicago Press, Chicago, IL.

Campbell, A., Converse, P. E., Miller, W. E. \& Stokes, D. E. (1960), The American Voter, John Wiley \& Sons, New York.

Campbell, D. E. \& Monson, J. Q. (2008), 'The religion card: Gay marriage and the 2004 presidential election', Public Opinion Quarterly 72(3), 399-419.

Castells, M. (1983), The City and the Grassroots: A Cross-Cultural Theory of Urban Social Movements, University of California Press, Berkeley, CA. 
Coe, K., Bruce, R. J. \& Ratcliff, C. L. (2017), ‘Presidential communication about marginalized groups: Applying a new analytic framework in the context of thee lgbt community', Journal of Communication 67(6), 851-873.

Conron, K. J., Luhur, W. \& Goldberg, S. K. (2020), Estimated Number of US LGBT Adults in Large Metropolitan Statistical Areas (MSAs), The Williams Institute, UCLA, Los Angeles, CA.

Crenshaw, K. (1993), '“mapping the margins: Intersectionality, identity politics, and violence against women of color', Stanford Law Review 43, 1241-1293.

Dahl, R. A. (1967), 'The city in the future of democracy', The American Political Sccience Review 61(4), 953-970.

Doan, P. L. \& Higgins, H. (2011), 'The demise of queer space? resurgent gentrification and the assimilation of lgbt neighborhoods', Journal of Planning Education and Research 31(1), 6-25.

Downs, A. (1957), 'An economic theory of political action in a democracy', Journal of Political Economy 65(2), 135-150.

Drumheller, K. \& McQuay, B. (2010), 'Living in the buckle: Promoting lgbt outreach services in conservative urban/rural centers', Journal of Communication 60(1).

Edelman, M. S. (1993), 'Understanding the gay and lesbian vote in '92', Public Perspective $4(3), 32-33$.

Egan, P. J., Edelman, M. \& Sherrill, K. (2009), Findings from the Hunter College Poll of Lesbians, Gays and Bisexuals: New Discoveries about Identity, Political Attitudes, and Civic Engagement, Hunter College, New York City, NY.

Enos, R. D. (2017), The Space Between Us: Social Geography and Politics, Cambridge University Press, Cambridge. 
Foos, F., John, P., Müller, C. \& Cunningham, K. (2021), 'Social Mobilization in Partisan Spaces', Journal of Politics Online First.

Ghaziani, A. (2015), There goes the gayborhood?, Princeton University Press, Princeton, NJ.

Gray, M. L. (2009), Out in the Country: Youth, Media, and Queer Visibility in Rural America, NYU Press, New York City, NY.

Haeberle, S. H. (1996), 'Gay men and lesbians at city hall', Social Science Quarterly 77(1), 190-197.

Hertzog, M. (1996), The Lavender Vote: Lesbians, Gay Men, and Bisexuals in American Electoral Politics, NYU Press, New York City, NY.

Huckfeldt, R., Plutzer, E. \& Sprague, J. (1993), 'Alternative Contexts of Political Behaviour: Churches, Neighbourhoods, and Individuals', Journal of Politics 55(2), 365-381.

Kissack, T. (1995), 'Freaking fag revolutionaries: New york's gay liberation front, 19691971', Radical History Review 62, 104-134.

Klandermans, B. (2002), 'How group identification helps to overcome the dilemma of collective action', American Behavioral Scientist 45(5), 887-900.

Klarman, M. (2014), The Space Between Us: Social Geography and Politics, Oxford University Press, Oxford.

Lewis, G. B., Rogers, M. A. \& Sherrill, K. (2011), 'Lesbian, gay, and bisexual voters in the 2000 u.s. presidential election', Politics and Policy 39(5), 655-677.

Lipset, S. (1983), Political Man: Social Basis of Politics, Heinemann, London.

Mattson, G. (2020), 'Small-city gay bars, big-city urbanism', City Community 19(1), 76-97.

McClendon, G. H. (2014), 'Social esteem and participation in contentious politics: A field experiment at an lgbt pride rally', American Journal of Political Science 58(2), 279-290. 
McGirr, L. (2015), Suburban Warriors: The Origins of the New American Right, Princeton University Press, Princeton, NJ.

Nemerever, Z. \& Rogers, M. (2021), 'Measuring the rural continuum in political science', Political Analysis 29(3), 267-286.

Newman, B. J., Velez, Y. \& Pearson-Merkowitz, S. (2016), 'Diversity of a different kind: Gentrification and its impact on social capital and political participation in black communities', Journal of Race, Ethnicity, and Politics 1(2), 316-347.

Olson, M. (1965), The Logic of Collective Action: Public Goods and the Theory of Groups, Harvard University Press, Cambridge, MA.

Ordona, T. A. (2000), Coming out together: An ethnohistory of the Asian and Pacific Islander Queer women's and transgendered people's movement of San Francisco, University of California, Santa Cruz, CA.

Orne, J. (2017), Boystown: Sex and Community in Chicago, University of Chicago Press, Chicago, IL.

Page, D. (2018), 'When does sexuality-based discrimination motivate political participation?', Political Psychology 39(5), 1013-1030.

Pantojo, A. D., Ramirez, R. \& Segura, G. M. (2001), 'Citizens by choice, voters by necessity: Patterns in political mobilization by naturalized latinos', Political Research Quarterly 54(4), 729-750.

Perez, V. M. (2014), ‘Political participation of lgbt americans', Project Vote .

Perrella, A. M., Brown, S. D. \& Kay, B. (2019), Profiles of the Lesbain, Gay, and Bisexual Electorate in Canada, in M. Tremblay, ed., 'Queering Representation: LGBTQ People and Electoral Politics in Canada', UBC Press, pp. 51-79. 
Putnam, R. D. (1966), 'Political Attitudes and Local Community', American Political Science Review 60(3), 640-654.

Ramirez, H. N. R. (2003), 'That's my place!: Negotiating racial, sexual, and gender politics in san francisco's gay latino alliance, 1975-1983', Journal of the History of Sexuality 12(2), 224-258.

Ramirez-Valles, J., Kuhns, L. M., Vazquez, R. \& Benjamin, G. D. (2014), 'Getting involved: Exploring latino gbt volunteerism and activism in aids and lgbt organizations', Journal of Gay and Lesbian Social Services 26(1), 18-36.

Renninger, B. J. (2018), 'Grindr killed the gay bar, and other attempts to blame social technologies for urban development: A democratic approach to popular technologies and queer sociality', Journal of Homosexuality 66(12), 1736-1755.

Rosenberg, R. (2016), 'The whiteness of gay urban belonging: Criminalizing lgbtq youth of color in queer spaces of care', Urban Geography 38(1), 137-148.

Rupp, L. J. \& Taylor, V. (2015), Drag Queens at the 801 Cabaret, University of Chicago Press, Chicago, IL.

Schaffner, B. \& Senic, N. (2006), 'Rights or benefits? explaining the sexual identity gap in american political behavior', Political Research Quarterly 59(1), 123-132.

Sherrill, K. \& Flores, A. (2014), ‘Consciousness, Identity, and Political Participation: The LGBT Voter in the 2012 Election.', Working paper .

Smets, K. \& van ham, C. (2013), “"the embarrassment of riches? a meta-analysis of individual-level research on voter turnout', Electoral Studies 32(2), 344-359.

Stewart-Winter, T. (2015), Queer Clout: Chicago and the Rise of Gay Politics, Pennsylvania University Press, Philadelphia, PA. 
Stone, A. L. (2018), 'The geography of research on lgbtq life: Why sociologists should study the south, rural queers, and ordinary cities', Sociology Compass 12, 1-15.

Swank, E. (2019), 'The political distinctiveness of gays and lesbians: Explaining protest actions across sexual identities', Politics, Groups, and Identities 7(1), 1-20.

Swank, E. \& Fahs, B. (2013), 'Predicting electoral activism among gays and lesbians in the united states', Journal of Applied Social Psychology 43(7), 1382-1393.

Swank, E. \& Fahs, B. (2019), 'Explaining the sexuality gap in protest participation', Journal of Homosexuality 66(3), 324-248.

Tarrow, S. (2011), Power in Movement: Social Movements and Contentious Politics, Cambridge University Press, Cambridge, UK.

Tavares, A. F. \& Carr, J. B. (2016), 'So close, yet so far away? the effects of city size, density, and growth on local civic participation', Journal of Urban Affairs 35(3), 283-302.

Turnbull-Dugarte, S. J. (2020), 'Cross-pressures and the european lavender vote: testing the conditionality of the sexuality gap', Electoral Studies 68.

Turnbull-Dugarte, S. J. \& Townsley, J. (2020), ‘Political engagement and turnout among same-sex couples in western europe', Research and Politics 7(4), 1-8.

Turnbull-Dugarte, S. J. (2020), 'Who wins the UK lavender vote? (Mostly) Labour', Politics, Groups, and Identities Online First.

Valentino, N. A., Brader, T., Groenendyk, E. W., Gregorowicz, K. \& Hutchings, V. L. (2011), 'Election night's alright for fighting: The role of emotions in political participation', Journal of Politics 73(1), 156-170.

Weston, K. (1995), 'Get thee to a big city: Sexual imaginary and the great gay migration', GLQ: A Journal of Gay and Lesbian Studies 2(3), 253-277. 


\section{Table A1: Balance test between LGBT and heterosexual samples}

\begin{tabular}{|c|c|c|c|c|c|c|c|}
\hline & & \multicolumn{2}{|c|}{ Heterosexual (N=54549) } & \multicolumn{2}{|c|}{ LGBT $(\mathrm{N}=7014)$} & \multirow{3}{*}{$\begin{array}{l}\text { Diff. in Means } \\
0.1\end{array}$} & \multirow{3}{*}{$\begin{array}{l}\text { Std. Error } \\
0.0\end{array}$} \\
\hline & & Mean & Std. Dev. & Mean & Std. Dev. & & \\
\hline \multicolumn{2}{|l|}{ Participation index } & 0.2 & 0.2 & 0.2 & 0.3 & & \\
\hline \multicolumn{2}{|l|}{ Age } & 49.7 & 17.5 & 38.6 & 15.7 & -11.1 & 0.2 \\
\hline \multicolumn{2}{|l|}{ Percent LGBT in locality } & 0.0 & 0.0 & 0.0 & 0.0 & 0.0 & 0.0 \\
\hline \multirow{2}{*}{\multicolumn{2}{|c|}{$\begin{array}{l}\text { Percent Black in locality } \\
\text { Percent Hispanic in locality }\end{array}$}} & 0.1 & 0.1 & 0.1 & 0.1 & 0.0 & 0.0 \\
\hline & & 0.2 & 0.2 & 0.2 & 0.1 & 0.0 & 0.0 \\
\hline \multicolumn{2}{|l|}{ Percent Asian in locality } & 0.1 & 0.1 & 0.1 & 0.1 & 0.0 & 0.0 \\
\hline \multicolumn{2}{|c|}{ Percent Other race in locality } & 0.0 & 0.0 & 0.0 & 0.0 & 0.0 & 0.0 \\
\hline \multirow{2}{*}{\multicolumn{2}{|c|}{$\begin{array}{l}\text { Percent Mixed race in locality } \\
\text { Percent No-white in locality }\end{array}$}} & 0.0 & 0.0 & 0.1 & 0.0 & 0.0 & 0.0 \\
\hline & & 0.4 & 0.2 & 0.4 & 0.2 & 0.0 & 0.0 \\
\hline & & $\mathbf{N}$ & $\%$ & $\mathbf{N}$ & $\%$ & & \\
\hline \multirow{6}{*}{ Race } & Asian & 1643 & 3.0 & 188 & 2.7 & & \\
\hline & Black & 6166 & 11.3 & 782 & 11.1 & & \\
\hline & Hispanic & 4448 & 8.2 & 733 & 10.5 & & \\
\hline & Other & 1386 & 2.5 & 175 & 2.5 & & \\
\hline & Two or more races & 1140 & 2.1 & 208 & 3.0 & & \\
\hline & White & 39203 & 71.9 & 4928 & 70.3 & & \\
\hline \multirow{2}{*}{ Gender } & Male & 22528 & 41.3 & 3264 & 46.5 & & \\
\hline & Female & 31458 & 57.7 & 3750 & 53.5 & & \\
\hline \multirow{6}{*}{ Education } & 2 -year college & 5832 & 10.7 & 704 & 10.0 & & \\
\hline & 4-year college & 12500 & 22.9 & 1649 & 23.5 & & \\
\hline & High school graduate & 14954 & 27.4 & 1676 & 23.9 & & \\
\hline & No High School & 1705 & 3.1 & 275 & 3.9 & & \\
\hline & Post-grad & 7423 & 13.6 & 951 & 13.6 & & \\
\hline & Some college & 11572 & 21.2 & 1759 & 25.1 & & \\
\hline \multirow[t]{4}{*}{ Urbanicity (subjective) } & City & 14018 & 25.7 & 2647 & 37.7 & & \\
\hline & Rural area & 10763 & 19.7 & 934 & 13.3 & & \\
\hline & Suburb & 21071 & 38.6 & 2410 & 34.4 & & \\
\hline & Town & 7823 & 14.3 & 985 & 14.0 & & \\
\hline \multirow{9}{*}{ Urbanicity (objective) } & Metro adj, urban pop ¡2.5k & 410 & 0.8 & 36 & 0.5 & & \\
\hline & Metro adj, urban pop $2.5 \mathrm{k}+$ & 2483 & 4.6 & 245 & 3.5 & & \\
\hline & Metro adj, urban pop $20 \mathrm{k}+$ & 2596 & 4.8 & 297 & 4.2 & & \\
\hline & Metro nonadj, urban pop $\mathrm{i} 2.5 \mathrm{k}$ & 618 & 1.1 & 35 & 0.5 & & \\
\hline & Metro nonadj, urban pop $2.5 \mathrm{k}+$ & 1379 & 2.5 & 136 & 1.9 & & \\
\hline & Metro nonadj, urban pop $20 \mathrm{k}+$ & 813 & 1.5 & 85 & 1.2 & & \\
\hline & Metro, $\mathrm{i} 250 \mathrm{k}$ & 5272 & 9.7 & 597 & 8.5 & & \\
\hline & Metro, 1 million+ & 28583 & 52.4 & 4040 & 57.6 & & \\
\hline & Metro, 250k-1 million & 12293 & 22.5 & 1530 & 21.8 & & \\
\hline \multirow{5}{*}{ Immigration status } & I am an immigrant to the USA and a naturalized citizen & 2891 & 5.3 & 509 & 7.3 & & \\
\hline & I am an immigrant to the USA but not a citizen & 896 & 1.6 & 114 & 1.6 & & \\
\hline & I was born in the USA but at least one of my parents is an immigrant & 5167 & 9.5 & 795 & 11.3 & & \\
\hline & My parents and I were born in the USA but at least one of my grandparents was an immigrant & 10746 & 19.7 & 1119 & 16.0 & & \\
\hline & My parents, grandparents and I were all born in the USA & 34157 & 62.6 & 4463 & 63.6 & & \\
\hline
\end{tabular}

\section{Appendix}




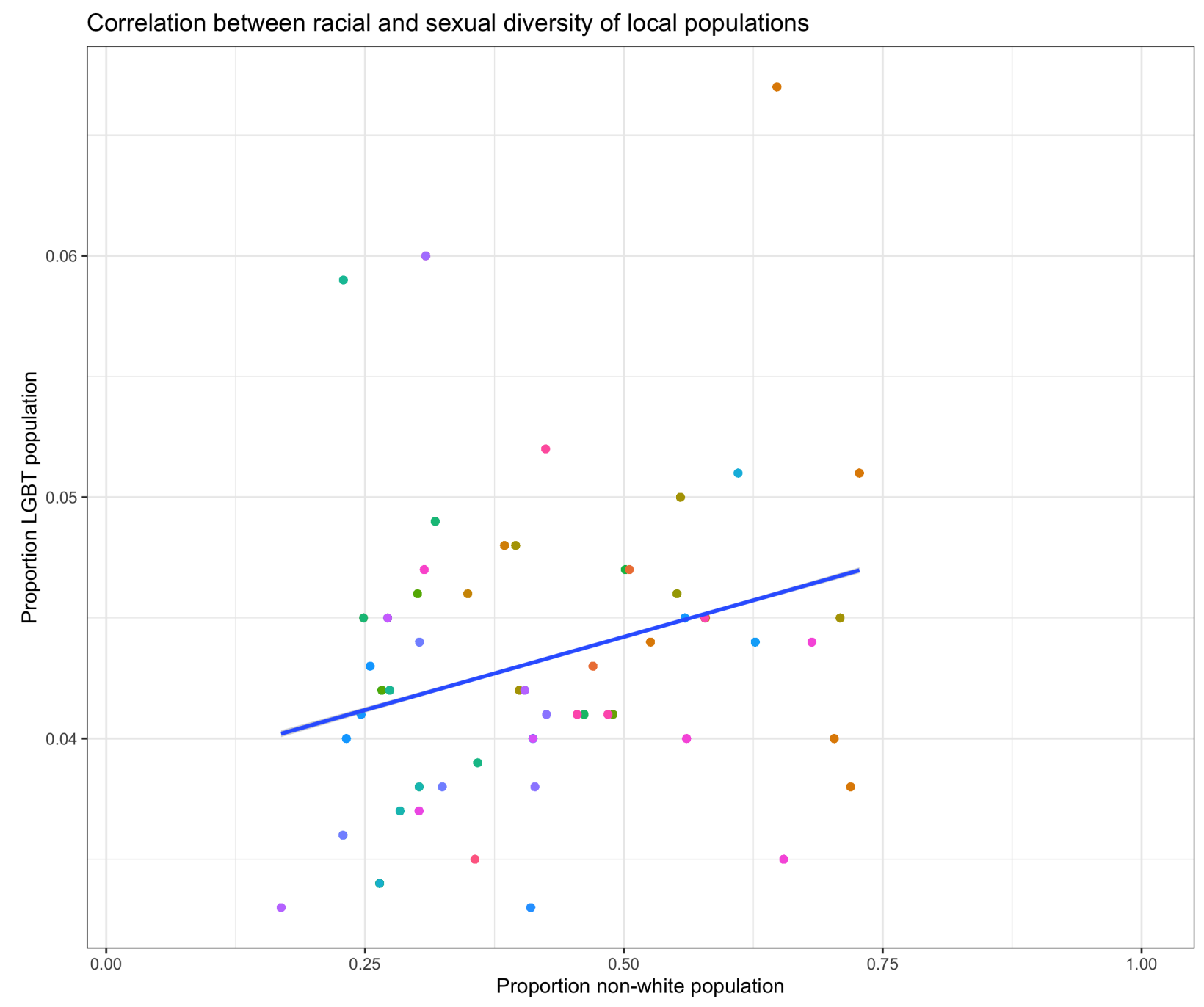

Figure A1: Level-2 variable correlation 
Primary regression output 
Table A2: Regression output for Figure 1

\begin{tabular}{|c|c|}
\hline \multirow[b]{2}{*}{ LGBT } & \\
\hline & $\begin{array}{r}\text { Model } 1 \\
0.081^{* * *} \\
(0.005)\end{array}$ \\
\hline Gender (female) & $\begin{array}{c}-0.021^{* * *} \\
(0.002)\end{array}$ \\
\hline Age & $\begin{array}{r}0.002^{* * * *} \\
(0.000)\end{array}$ \\
\hline $\mathrm{Age}^{2}$ & $\begin{array}{l}0.000^{* *} \\
(0.000)\end{array}$ \\
\hline \multicolumn{2}{|l|}{ Race (baseline: White) } \\
\hline Black & $\begin{array}{c}-0.063^{* * *} \\
(0.004)\end{array}$ \\
\hline Hispanic & $\begin{array}{c}-0.056^{* * *} \\
(0.005)\end{array}$ \\
\hline Asian & $\begin{array}{c}-0.054^{* * *} \\
(0.007)\end{array}$ \\
\hline Multi-racial & $\begin{array}{c}0.020 \\
(0.013)\end{array}$ \\
\hline Other & $\begin{array}{l}-0.003 \\
(0.009)\end{array}$ \\
\hline \multicolumn{2}{|c|}{ Citizenship (baseline: 3rd gen. American) } \\
\hline 2nd gen. American & $\begin{array}{c}0.037^{* * * *} \\
(0.003)\end{array}$ \\
\hline 1st gen. American & $\begin{array}{c}0.025^{* * *} \\
(0.005)\end{array}$ \\
\hline Non-naturalised resident & $\begin{array}{r}-0.062^{* * * *} \\
(0.006)\end{array}$ \\
\hline Naturalised citizen & $\begin{array}{l}-0.006 \\
(0.006)\end{array}$ \\
\hline Constant & $\begin{array}{c}0.111^{* * *} \\
(0.011)\end{array}$ \\
\hline $\mathrm{N}$ & 51431 \\
\hline R2 & 0.039 \\
\hline R2 Adj. & 0.039 \\
\hline AIC & -761.5 \\
\hline BIC & -628.7 \\
\hline Log.Lik. & 395.735 \\
\hline $\mathrm{F}$ & 162.017 \\
\hline
\end{tabular}


Table A3: Regression output for Figure 2

\begin{tabular}{|c|c|}
\hline & Model 1 \\
\hline LGBT & $\begin{array}{r}0.076^{* * *} \\
(0.008)\end{array}$ \\
\hline Gender (female) & $\begin{array}{r}-0.022^{* * *} \\
(0.003)\end{array}$ \\
\hline Race (baseline: White) & \\
\hline Black & $\begin{array}{c}-0.069^{* * *} \\
(0.007)\end{array}$ \\
\hline Hispanic & $\begin{array}{c}-0.048^{* * *} \\
(0.010)\end{array}$ \\
\hline Asian & $\begin{array}{c}-0.065^{* * *} \\
(0.009)\end{array}$ \\
\hline Multi-racial & $\begin{array}{c}0.021 \\
(0.021)\end{array}$ \\
\hline Other & $\begin{array}{c}0.006 \\
(0.016)\end{array}$ \\
\hline LGBT $\times$ female & $\begin{array}{l}0.017 \\
(0.011)\end{array}$ \\
\hline LGBT $\times$ Black & $\begin{array}{l}-0.020 \\
(0.022)\end{array}$ \\
\hline LGBT $\times$ Hispanic & $\begin{array}{l}-0.025 \\
(0.023)\end{array}$ \\
\hline LGBT $\times$ Asian & $\begin{array}{l}0.089^{*} \\
(0.046)\end{array}$ \\
\hline LGBT $\times$ Multi-racial & $\begin{array}{c}0.103 \\
(0.122)\end{array}$ \\
\hline LGBT $\times$ other & $\begin{array}{c}0.041 \\
(0.064)\end{array}$ \\
\hline Female $\times$ Black & $\begin{array}{l}0.015^{*} \\
(0.008)\end{array}$ \\
\hline Female $\times$ Hispanic & $\begin{array}{l}-0.012 \\
(0.011)\end{array}$ \\
\hline Female $\times$ Asian & $\begin{array}{c}0.010 \\
(0.011)\end{array}$ \\
\hline Female $\times$ Multi-racial & $\begin{array}{l}-0.011 \\
(0.024)\end{array}$ \\
\hline Female $\times$ Other & $\begin{array}{l}-0.013 \\
(0.019)\end{array}$ \\
\hline LGBT $\times$ female $\times$ Black & $\begin{array}{l}-0.026 \\
(0.030)\end{array}$ \\
\hline LGBT $\times$ female $\times$ Hispanic & $\begin{array}{c}0.024 \\
(0.032)\end{array}$ \\
\hline LGBT $\times$ female $\times$ Asian & $\begin{array}{l}-0.069 \\
(0.058)\end{array}$ \\
\hline LGBT $\times$ female $\times$ Multi-racial & $\begin{array}{c}-0.134 \\
(0.126)\end{array}$ \\
\hline LGBT $\times$ female $\times$ Other & $\begin{array}{l}-0.135^{*} \\
(0.072)\end{array}$ \\
\hline Age & $\begin{array}{r}0.002^{* * *} \\
(0.000)\end{array}$ \\
\hline $\mathrm{Age}^{2}$ & $\begin{array}{l}0.000^{* *} \\
(0.000)\end{array}$ \\
\hline Citizenship (baseline: 3rd gen. American) & \\
\hline 2nd gen. American & $\begin{array}{c}0.037^{* * *} \\
(0.003)\end{array}$ \\
\hline 1st gen. American & $\begin{array}{c}0.025^{* * *} \\
(0.005)\end{array}$ \\
\hline Non-naturalised resident & $\begin{array}{r}-0.062^{* * *} \\
(0.006)\end{array}$ \\
\hline Naturalised citizen & $\begin{array}{l}-0.005 \\
(0.006)\end{array}$ \\
\hline Constant & $\begin{array}{r}0.110^{* * *} \\
(0.011)\end{array}$ \\
\hline N. & 51431 \\
\hline $\mathrm{R} 2$ & 0.041 \\
\hline R2 Adj. & 0.040 \\
\hline AIC & -795.0 \\
\hline $\mathrm{BIC}$ & -520.8 \\
\hline Log.Lik. & 428.522 \\
\hline $\mathrm{F}$ & 74.960 \\
\hline
\end{tabular}


Table A4: Regression output for Figure 3

\begin{tabular}{|c|c|c|c|c|c|c|}
\hline & Attend meeting & Political sign & Campaign volunteer & Attend protest & Contact politician & Donate \\
\hline \multirow[t]{2}{*}{ LGBT } & $0.035^{* * *}$ & $0.090^{* * *}$ & $0.045^{* * *}$ & $0.077^{* * *}$ & $0.105^{* * *}$ & $0.134^{* * *}$ \\
\hline & $(0.006)$ & $(0.008)$ & $(0.005)$ & $(0.007)$ & $(0.009)$ & $(0.009)$ \\
\hline \multirow[t]{2}{*}{ Gender (female) } & $-0.027^{* * *}$ & $-0.027^{* * *}$ & $-0.005^{* *}$ & $-0.011^{* * *}$ & $-0.017^{* * *}$ & $-0.040^{* * *}$ \\
\hline & $(0.003)$ & $(0.004)$ & $(0.002)$ & $(0.003)$ & $(0.005)$ & $(0.005)$ \\
\hline \multicolumn{7}{|l|}{ Race (baseline: White) } \\
\hline \multirow[t]{2}{*}{ Black } & $-0.017^{* * *}$ & $-0.092^{* * *}$ & $-0.014^{* * *}$ & $-0.020^{* * *}$ & $-0.125^{* * *}$ & $-0.110^{* * *}$ \\
\hline & $(0.005)$ & $(0.007)$ & $(0.004)$ & $(0.006)$ & $(0.007)$ & $(0.008)$ \\
\hline \multirow[t]{2}{*}{ Hispanic } & $-0.030^{* * *}$ & $-0.068^{* * *}$ & $-0.027^{* * *}$ & $-0.022^{* * *}$ & $-0.104^{* * *}$ & $-0.085^{* * *}$ \\
\hline & $(0.006)$ & $(0.009)$ & $(0.005)$ & $(0.007)$ & $(0.010)$ & $(0.011)$ \\
\hline \multirow[t]{2}{*}{ Asian } & $-0.018^{*}$ & $-0.100^{* * *}$ & $-0.024^{* * *}$ & $-0.025^{* * *}$ & $-0.105^{* * *}$ & $-0.054^{* * *}$ \\
\hline & $(0.010)$ & $(0.011)$ & $(0.007)$ & $(0.008)$ & $(0.012)$ & $(0.015)$ \\
\hline \multirow[t]{2}{*}{ Multi-racial } & $0.034^{* *}$ & 0.001 & 0.001 & $0.038^{* *}$ & 0.028 & 0.021 \\
\hline & $(0.016)$ & $(0.017)$ & $(0.014)$ & $(0.018)$ & $(0.018)$ & $(0.021)$ \\
\hline \multirow[t]{2}{*}{ Other } & 0.010 & $-0.023^{*}$ & 0.004 & 0.011 & 0.002 & -0.021 \\
\hline & $(0.012)$ & $(0.014)$ & $(0.008)$ & $(0.014)$ & $(0.016)$ & $(0.017)$ \\
\hline \multirow[t]{2}{*}{ Age } & $0.002^{* * *}$ & $0.004^{* * *}$ & $-0.001^{* * *}$ & $-0.002^{* * *}$ & $0.009^{* * *}$ & -0.002 \\
\hline & $(0.001)$ & $(0.001)$ & $(0.000)$ & $(0.001)$ & $(0.001)$ & $(0.001)$ \\
\hline \multirow[t]{2}{*}{ Age $^{2}$} & $0.000^{* * *}$ & $0.000^{* * *}$ & $0.000^{* * *}$ & 0.000 & $0.000^{* * *}$ & $0.000^{* * *}$ \\
\hline & $(0.000)$ & $(0.000)$ & $(0.000)$ & $(0.000)$ & $(0.000)$ & $(0.000)$ \\
\hline \multicolumn{7}{|c|}{ Citizenship (baseline: 3rd gen. American) } \\
\hline \multirow[t]{2}{*}{ 2nd gen. American } & $0.020^{* * *}$ & $0.017^{* * *}$ & $0.021^{* * *}$ & $0.032^{* * *}$ & $0.058^{* * *}$ & $0.074^{* * *}$ \\
\hline & $(0.004)$ & $(0.006)$ & $(0.003)$ & $(0.004)$ & $(0.006)$ & $(0.007)$ \\
\hline \multirow[t]{2}{*}{ 1st gen. American } & 0.008 & 0.010 & $0.025^{* * *}$ & $0.022^{* * *}$ & $0.024^{* * *}$ & $0.061^{* * *}$ \\
\hline & $(0.006)$ & $(0.008)$ & $(0.005)$ & $(0.006)$ & $(0.009)$ & $(0.010)$ \\
\hline \multirow[t]{2}{*}{ Non-naturalised citizen } & $-0.029^{* * *}$ & $-0.087^{* * *}$ & $-0.019^{* * *}$ & $-0.044^{* * *}$ & $-0.074^{* * *}$ & $-0.120^{* * *}$ \\
\hline & $(0.009)$ & $(0.013)$ & $(0.006)$ & $(0.008)$ & $(0.015)$ & $(0.015)$ \\
\hline \multirow[t]{2}{*}{ Naturalised citizen } & 0.007 & -0.011 & $0.017^{* * *}$ & 0.012 & $-0.041^{* * *}$ & -0.019 \\
\hline & $(0.008)$ & $(0.011)$ & $(0.006)$ & $(0.008)$ & $(0.010)$ & $(0.012)$ \\
\hline \multirow[t]{2}{*}{ Constant } & $0.059^{* * *}$ & $0.097^{* * *}$ & $0.080^{* * *}$ & $0.179^{* * *}$ & 0.008 & $0.242^{* * *}$ \\
\hline & $(0.015)$ & $(0.021)$ & $(0.012)$ & $(0.016)$ & $(0.019)$ & $(0.023)$ \\
\hline $\mathrm{N}$ & 51431 & 51431 & 51431 & 51431 & 51431 & 51431 \\
\hline $\mathrm{R} 2$ & 0.008 & 0.020 & 0.008 & 0.024 & 0.033 & 0.041 \\
\hline R2 Adj. & 0.007 & 0.020 & 0.007 & 0.024 & 0.033 & 0.041 \\
\hline AIC & 23000.1 & 59612.1 & 1864.2 & 23406.8 & 66869.0 & 73161.8 \\
\hline $\mathrm{BIC}$ & 23132.9 & 59744.8 & 1996.9 & 23539.5 & 67001.7 & 73294.6 \\
\hline Log.Lik. & -11485.071 & -29791.063 & -917.082 & -11688.411 & -33419.483 & -36565.918 \\
\hline F & 30.251 & 80.475 & 30.373 & 96.879 & 134.720 & 171.051 \\
\hline
\end{tabular}

Robust standard errors in parenthesis

${ }^{*} \mathrm{p}<0.1,{ }^{* *} \mathrm{p}<0.05,{ }^{* * *} \mathrm{p}<0.01$ 
Table A5: Regression output for Figure 4

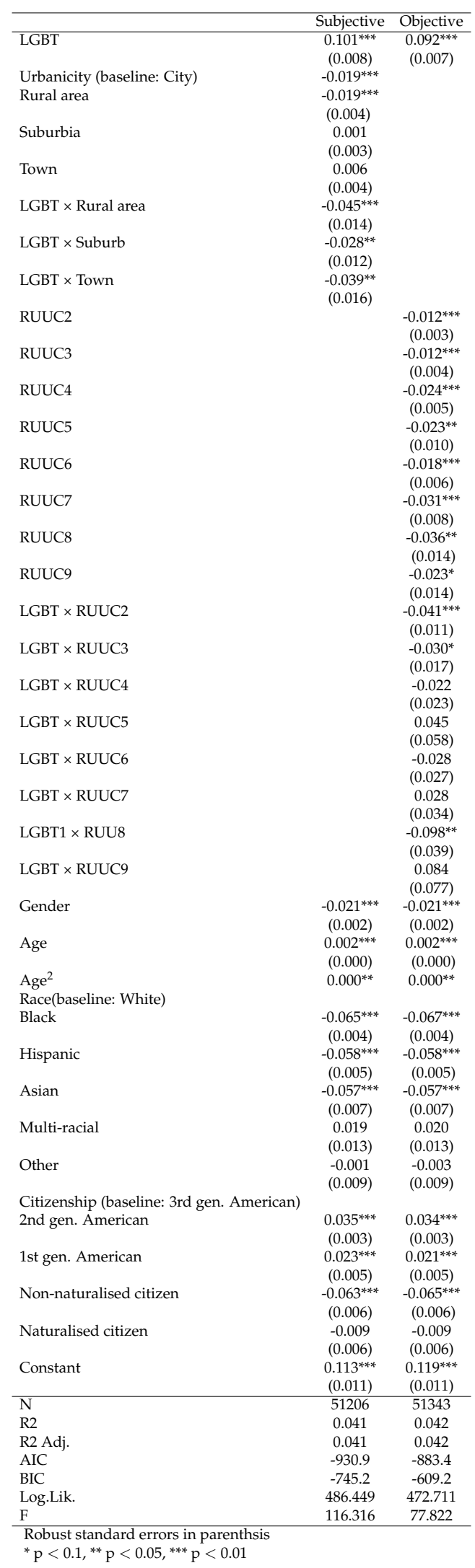


Table A6: Multi-level model regression outputs for Figure 5

\begin{tabular}{|c|c|c|}
\hline & Main test & Gendered effects \\
\hline \multirow[t]{2}{*}{ LGBT } & -0.008 & -0.013 \\
\hline & $(0.030)$ & $(0.040)$ \\
\hline \multirow[t]{2}{*}{ \% LGBTpop } & $0.874^{*}$ & 0.120 \\
\hline & $(0.480)$ & $(0.550)$ \\
\hline \multirow[t]{2}{*}{ Gender (female) } & $-0.038^{* * *}$ & $-0.099 * * *$ \\
\hline & $(0.003)$ & $(0.022)$ \\
\hline \multirow[t]{2}{*}{ LGBT $\times \%$ LGBTpop } & $2.070^{* * * *}$ & $2.083^{* *}$ \\
\hline & $(0.664)$ & $(0.887)$ \\
\hline \multirow[t]{2}{*}{ LGBT $\times$ Female } & & -0.012 \\
\hline & & $(0.061)$ \\
\hline \multirow[t]{2}{*}{$\%$ LGBT $\times$ Female } & & $1.355^{* * *}$ \\
\hline & & $(0.486)$ \\
\hline \multirow[t]{2}{*}{ LGBT $\times \%$ LGBTpop $\times$ Female } & & 0.514 \\
\hline & & (1.345) \\
\hline \multirow[t]{2}{*}{$\%$ non-white pop } & 0.000 & 0.000 \\
\hline & $(0.020)$ & $(0.020)$ \\
\hline \multirow[t]{2}{*}{ Age } & $0.001^{* * *}$ & $0.001^{* * *}$ \\
\hline & $(0.000)$ & $(0.000)$ \\
\hline \multirow[t]{2}{*}{ Age $^{2}$} & $0.000^{* *}$ & $0.000^{* *}$ \\
\hline & $(0.000)$ & $(0.000)$ \\
\hline \multicolumn{3}{|l|}{ Race (baseline: White) } \\
\hline \multirow[t]{2}{*}{ Black } & $-0.065^{* * *}$ & $-0.065^{* * *}$ \\
\hline & $(0.004)$ & $(0.004)$ \\
\hline \multirow[t]{2}{*}{ Hispanic } & $-0.040^{* * *}$ & $-0.040^{* * *}$ \\
\hline & $(0.005)$ & $(0.005)$ \\
\hline \multirow[t]{2}{*}{ Asian } & $-0.054^{* * *}$ & $-0.055^{* * *}$ \\
\hline & $(0.008)$ & $(0.008)$ \\
\hline \multirow[t]{2}{*}{ Multi-racial } & $0.023^{* *}$ & $0.022^{* *}$ \\
\hline & $(0.009)$ & $(0.009)$ \\
\hline \multirow[t]{2}{*}{ Other } & 0.013 & 0.013 \\
\hline & $(0.008)$ & $(0.008)$ \\
\hline \multicolumn{3}{|c|}{ Citizenship (baseline: 3rd gen. American) } \\
\hline \multirow[t]{2}{*}{ 2nd gen. American } & $0.030^{* * *}$ & $0.030^{* * *}$ \\
\hline & $(0.004)$ & $(0.004)$ \\
\hline \multirow[t]{2}{*}{ 1st gen. American } & 0.006 & 0.006 \\
\hline & $(0.005)$ & $(0.005)$ \\
\hline \multirow[t]{2}{*}{ Non-naturalised citizen } & $-0.085^{* * *}$ & $-0.085^{* * *}$ \\
\hline & $(0.011)$ & $(0.011)$ \\
\hline \multirow{2}{*}{ Naturalised citizen } & $-0.017^{* * *}$ & $-0.016^{* * *}$ \\
\hline & $(0.006)$ & $(0.006)$ \\
\hline \multirow[t]{2}{*}{ Constant } & $0.115^{* * *}$ & $0.147^{* * *}$ \\
\hline & $(0.024)$ & $(0.027)$ \\
\hline $\mathrm{N}$ & 27641 & 27641 \\
\hline R2 Marg. & 0.047 & 0.048 \\
\hline R2 Cond. & 0.053 & 0.053 \\
\hline AIC & -3929.1 & -3930.1 \\
\hline $\mathrm{BIC}$ & -3772.8 & -3749.1 \\
\hline ICC & 0.0 & 0.0 \\
\hline RMSE & 0.22 & 0.22 \\
\hline
\end{tabular}

Standard errors in parenthesis

${ }^{*} \mathrm{p}<0.1,{ }^{* *} \mathrm{p}<0.05,{ }^{* * *} \mathrm{p}<0.01$ 


\section{Robustness and sensitivity tests}
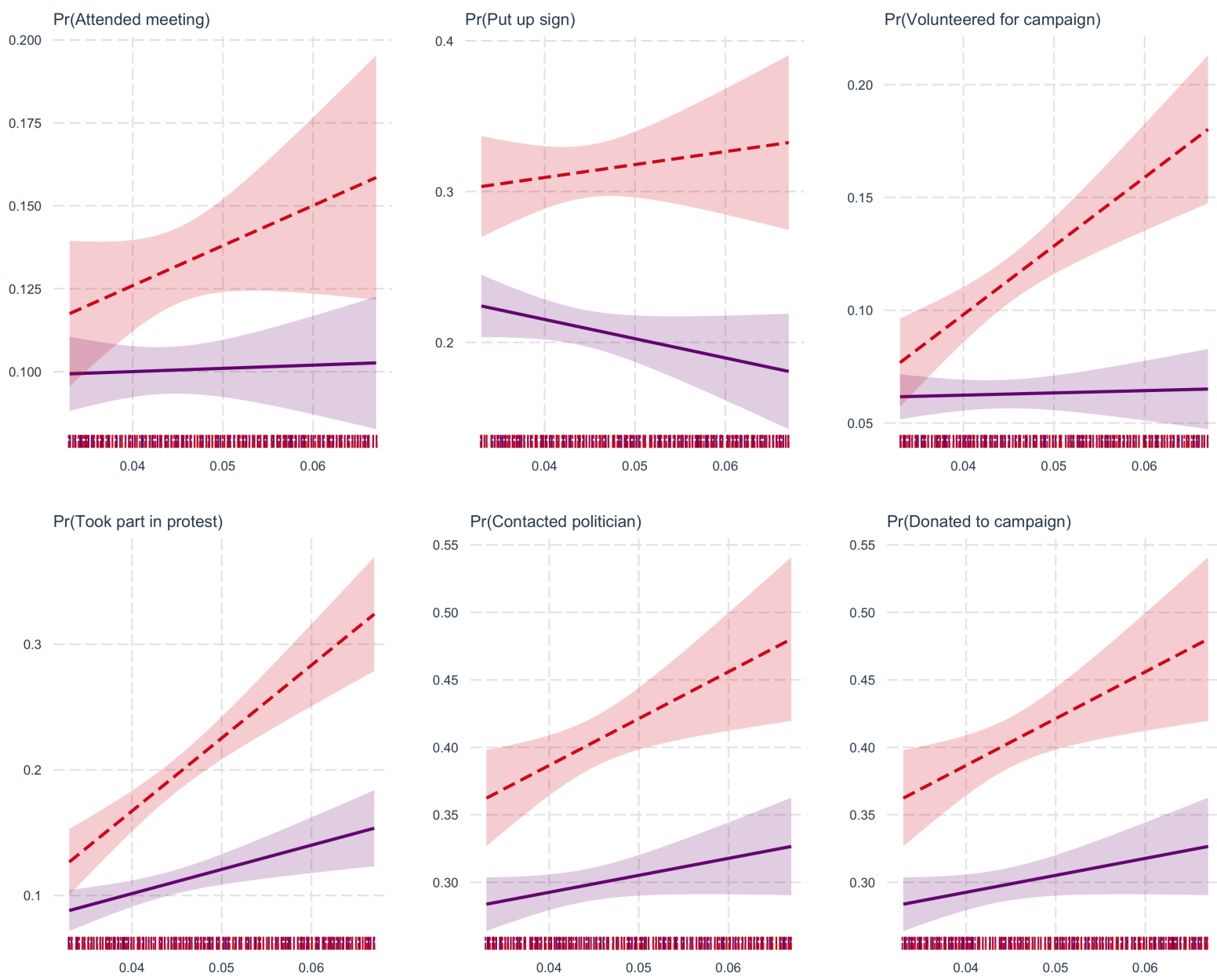

Figure A2: Moderation effects across independent participation items 


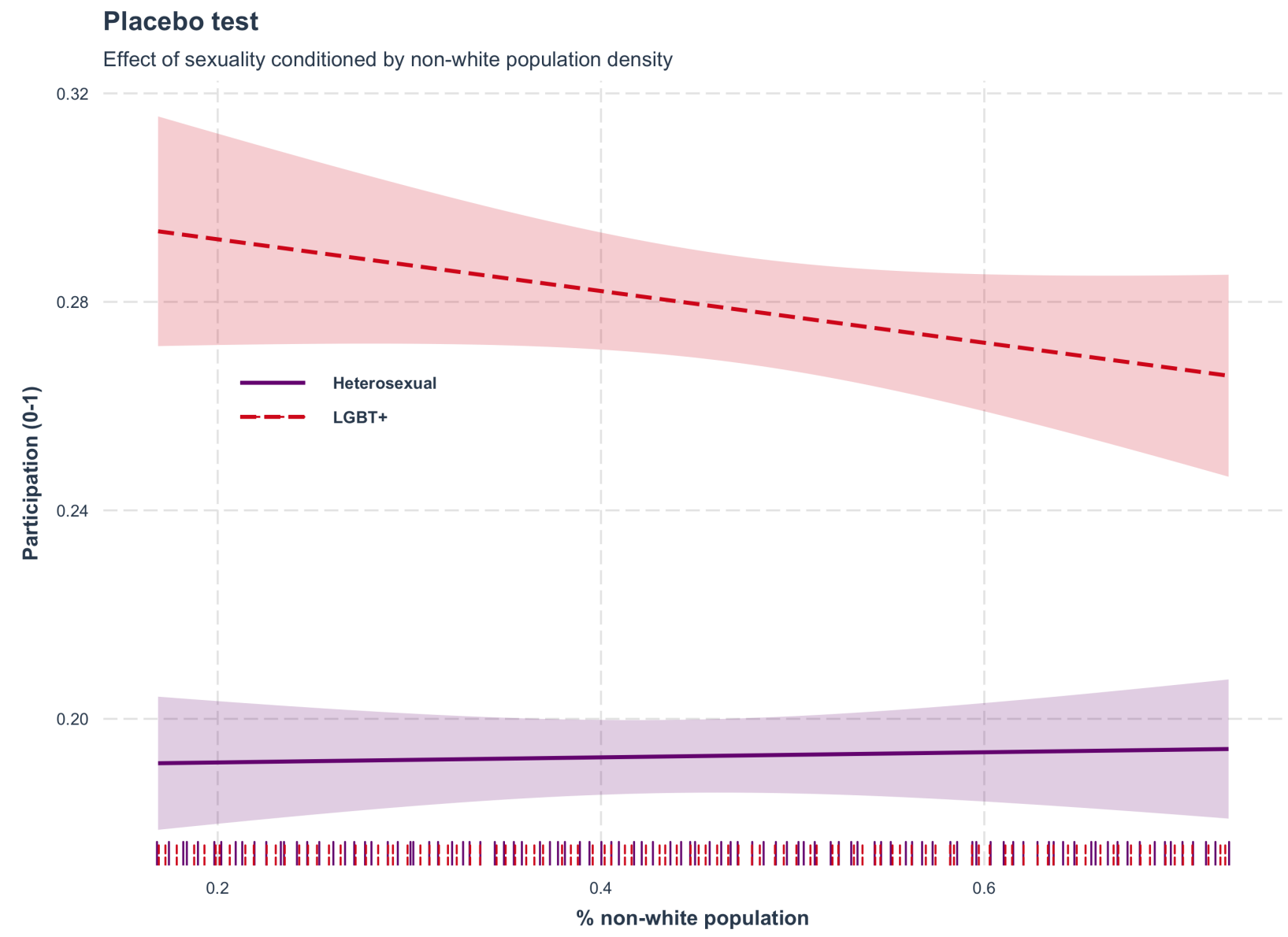

Figure A3: Robustness test using placebo moderator variable 